\title{
Long-Term Oocyte-Like Cell Development in Cultures Derived from Neonatal Marmoset Monkey Ovary
}

\author{
Bentolhoda Fereydouni, ${ }^{1}$ Gabriela Salinas-Riester, ${ }^{2}$ Michael Heistermann, ${ }^{3}$ \\ Ralf Dressel, ${ }^{4}$ Lucia Lewerich, ${ }^{1}$ Charis Drummer, ${ }^{1}$ and Rüdiger Behr ${ }^{1}$ \\ ${ }^{1}$ Stem Cell Biology Unit, German Primate Center-Leibniz Institute for Primate Research, Kellnerweg 4, 37077 Göttingen, Germany \\ ${ }^{2}$ Microarray and Deep-Sequencing Core Facility, University Medical Center Göttingen (UMG), Justus-von-Liebig-Weg 11, \\ 37077 Göttingen, Germany \\ ${ }^{3}$ Endocrinology Laboratory, German Primate Center-Leibniz Institute for Primate Research, Kellnerweg 4, 37077 Göttingen, Germany \\ ${ }^{4}$ Department of Cellular and Molecular Immunology, University of Göttingen, Humboldtallee 34, 37073 Göttingen, Germany
}

Correspondence should be addressed to Rüdiger Behr; rbehr@dpz.eu

Received 28 May 2015; Revised 28 July 2015; Accepted 28 July 2015

Academic Editor: Irma Virant-Klun

Copyright (C) 2016 Bentolhoda Fereydouni et al. This is an open access article distributed under the Creative Commons Attribution License, which permits unrestricted use, distribution, and reproduction in any medium, provided the original work is properly cited.

\begin{abstract}
We use the common marmoset monkey (Callithrix jacchus) as a preclinical nonhuman primate model to study reproductive and stem cell biology. The neonatal marmoset monkey ovary contains numerous primitive premeiotic germ cells (oogonia) expressing pluripotent stem cell markers including OCT4A (POU5F1). This is a peculiarity compared to neonatal human and rodent ovaries. Here, we aimed at culturing marmoset oogonia from neonatal ovaries. We established a culture system being stable for more than 20 passages and 5 months. Importantly, comparative transcriptome analysis of the cultured cells with neonatal ovary, embryonic stem cells, and fibroblasts revealed a lack of germ cell and pluripotency genes indicating the complete loss of oogonia upon initiation of the culture. From passage 4 onwards, however, the cultured cells produced large spherical, free-floating cells resembling oocyte-like cells (OLCs). OLCs strongly expressed several germ cell genes and may derive from the ovarian surface epithelium. In summary, our novel primate ovarian cell culture initially lacked detectable germ cells but then produced OLCs over a long period of time. This culture system may allow a deeper analysis of early phases of female primate germ cell development and-after significant refinement-possibly also the production of monkey oocytes.
\end{abstract}

\section{Introduction}

It is a long-held opinion in reproductive biology that in females of most species, including the human, the postnatal germ cell pool is limited in number and cannot be replenished or even expanded. Early studies in the rat showed that oogonia, the proliferating female germ line progenitor cells that enter meiosis to produce oocytes, were found only during fetal development [1]. Human females are also thought to be born with a nonrenewable pool of germ cell follicles which declines with age [2]. In postnatal human ovaries, oogonia were found only very sporadically and were undetectable by the age of two years [3]. A lack of evidence for postnatal germ cell proliferation in human ovaries was also reported by Liu et al. [4]. Instead, by far most of the proliferation-competent oogonia in the human ovary entered meiosis by the end of the second trimester of gestation $[5,6]$. Recent studies using transgenic mice and nonhuman primates also reported a lack of evidence for germ cell proliferation in adult mouse $[7,8]$ and monkey [9] ovaries. However, these data supporting the view of a fixed postnatal female germ cell pool are profoundly challenged by reports starting a decade ago $[10,11]$, suggesting replenishment of the ovarian germ cell pool in mice. The existence of mitotically active germ line stem cells in postnatal mouse and human ovaries was suggested by the isolation, molecular characterization, and transplantation of cell populations [10, 12]. Probably the strongest evidence so far for a germ line stem cell pool in the ovary was provided by Zou et al. [13], who generated mouse female germ line stem cells (FGSCs) with 
the ability to reconstitute oogenesis and produce offspring after transplantation. Other authors reported the production of oocyte-like cells in vitro from cultures of adult ovarian surface epithelium (OSE) [14-16]. In summary, currently there are several apparently contradictory reports which provide data supporting or negating generation of new oocytes in the postnatal rodent and primate-including the human-ovary. Adding to this complex situation, Dyce et al. [17] reported that even fetal porcine skin cells can form oocyte-like cells (OLCs) in vitro.

We use the common marmoset monkey (Callithrix jacchus) as a nonhuman primate model to study reproductive and stem cell biology. In contrast to other species used in reproductive biology, the marmoset monkey still has numerous oogonia in the neonatal ovary, which robustly express the pluripotency associated markers OCT4A, LIN28, and SALL4, the germ cell marker VASA, and the proliferation marker KI-67 [18]. Therefore, these oogonia in the neonatal marmoset ovary share important pluripotency markers with marmoset monkey embryonic stem (ES) cells [19]. We failed to detect this proliferating and pluripotency-marker-positive cell population in the one-year-old and adult ovary [18] indicating a fast postnatal oogonial clearing also in this nonhuman primate species. Here, we report studies on the culture of neonatal marmoset ovarian cells. We originally aimed at culturing the proliferating marmoset monkey oogonia exhibiting a pluripotency signature similar to marmoset monkey embryonic stem cells. Hence, we established a mouse embryonic fibroblast- (MEF-) based cell culture system, which allowed the long-term culture of ovarian cells. However, germ cell and pluripotency marker expression was lost in the first passages indicating the complete loss of the oogonia. After a few passages, however, germ cell marker expression recovered, and we observed in later passages the development of large spherical, free-floating cells which we called oocyte-like cells (OLCs) due to their morphological resemblance with the cells reported by Dyce et al. [17]. OLCs had a diameter up to $\sim 40 \mu \mathrm{m}$ and strongly expressed several germ cell markers. This study demonstrates the development of oocyte-like cells in long-term ovarian cell cultures from a translational and experimentally accessible nonhuman primate species.

\section{Materials and Methods}

2.1. Animals. Marmoset monkeys (Callithrix jacchus) for this study were obtained from the self-sustaining breeding colony of the German Primate Center (Deutsches Primatenzentrum; DPZ). The German Primate Center is registered and authorised by the local and regional veterinary governmental authorities (Reference number 122910.3311900, PK Landkreis Göttingen). Health and well-being of the animals were controlled daily by experienced veterinarians and animal care attendants. The legal guidelines for the use of animals and the institutional guidelines of the DPZ for the care and use of marmoset monkeys were strictly followed. The animals were pair-housed in a temperature- $\left(25 \pm 1^{\circ} \mathrm{C}\right)$ and humidity-controlled ( $65 \pm 5 \%)$ facility. Illumination was provided by daylight and additional artificial lighting on a $12.00: 12.00$-hour light : dark cycle. The animals were fed ad libitum with a pelleted marmoset diet (ssniff Spezialdiäten, Soest, Germany). In addition, $20 \mathrm{~g}$ mash per animal was served in the morning and $30 \mathrm{~g}$ cut fruits or vegetables mixed with noodles or rice was supplied in the afternoon. Furthermore, once per week mealworms or locusts were served in order to provide adequate nutrition. Drinking water was always available.

In captivity, marmosets sometimes give birth to triplets or even quadruplets. However, the mother is usually able to feed and rear only two neonates, which is the normal litter size of free-living marmosets. Therefore, the neonates from triplet births were used to collect organs for this study. Marmoset monkey ovaries were obtained from six neonatal animals (postnatal days 1-5). All animals were narcotized with Pentobarbital (Narcoren; $0.05 \mathrm{~mL}$ intramuscular) and euthanized by an experienced veterinarian with an intracardial injection of $0.5 \mathrm{~mL}$ Pentobarbital before a lack of nourishment caused suffering of the animals. Wherever applicable, the ARRIVE guidelines were followed.

2.2. Numbers of Animals. Altogether, ovaries from 6 neonatal marmosets were used in this study: 5 pairs for culture and one pair as reference for transcriptome analysis.

2.3. Neonatal Common Marmoset Monkey Ovarian Cell Cultures. Neonatal ovaries (approximate dimensions $2 \mathrm{~mm} \times$ $1 \mathrm{~mm} \times 1 \mathrm{~mm}$; see also [18]) were first collected and washed in a Petri dish containing cold DPBS. Fat and blood cells were removed and the whole ovary including the OSE was transferred to fresh buffer and minced with sterile scissors. Minced ovaries were then transferred to a $15 \mathrm{~mL}$ falcon tube. After gentle centrifugation, DPBS was removed and ovarian tissue fragments were resuspended in DMEM/F12 medium containing collagenase (Sigma \#C2674) and DNase and kept for 45 minutes at $37^{\circ} \mathrm{C}$. Every 5 to $10 \mathrm{~min}$ the ovaries were gently pipetted to disintegrate the tissue. Finally, 10\% FBS was added to inactivate the enzyme. In order to remove larger undigested tissue fragments, the cells were passed through $70 \mu \mathrm{m}$ strainer (BD, USA) and were centrifuged at $200 \mathrm{~g}$ for $10 \mathrm{~min}$. Then the supernatant was removed and the cells were resuspended in culture medium and transferred on a prepared feeder layer of mouse embryonic fibroblast (MEF) feeder at a concentration $3-5 \times 10^{5}$ cells per $5 \mathrm{~cm}$ well. After one week large colonies were individually picked with a microprobe (FST, Heidelberg, Germany, \#10032-13) and digested with Accutase (Life Technologies, Germany) for $4 \mathrm{~min}$. Then the cells were centrifuged at $300 \mathrm{~g}$ for 10 minutes and resuspended in the culture medium for further passages. Cultures were maintained at $37^{\circ} \mathrm{C}$ under $5 \% \mathrm{CO}_{2}$ and $5 \%$ oxygen in a humidified incubator.

2.4. Culturing Neonatal Common Marmoset Ovaries. Different cell culture conditions were tested. Finally this condition was selected: DMEM/F12 supplemented with FBS (10\%), Pen/Strep, amphotericin B, and human LIF $(10 \mu \mathrm{g} / \mathrm{mL})$ on an irradiated mouse embryonic fibroblast (MEF) feeder cell layer. For further passages (usually after 7-10 days) colonies 
were mechanically removed with a sterile probe, digested with Accutase, and placed on a newly prepared MEF layer.

2.5. Culturing Marmoset Monkey Embryonic Stem Cells. Marmoset monkey ES cells were basically cultured as described previously [20]. Only for passaging of the ES cells, StemPro Accutase (Life Technologies) was used instead of trypsinEDTA with subsequent mechanical dissociation.

2.6. Immunofluorescence Staining. For immunofluorescence staining, medium was removed and cell colonies were washed twice in PBS and then fixed in 4\% PFA for 15 minutes. Cells were permeabilized by $0.1 \%$ Triton X-100 in PBS for 10 minutes at room temperature. Primary antibody (VASA, R\&D Systems, AF2030) was diluted in 3\% BSA-PBS, and colonies were incubated for $1 \mathrm{~h}$ at $37^{\circ} \mathrm{C}$. Cells were washed twice in PBS. The secondary antibody, which was diluted in 3\% BSA-PBS, was added to the cells and incubated for 20 minutes in a dark box at $37^{\circ} \mathrm{C}$. Cells were washed again twice in PBS and 5\% DAPI-PBS was added. Cells were washed again with PBS and mounted with CitiFluor (Science Services AF1, Glycerol/PBS solution). For negative controls, the primary antibody was (i) omitted or (ii) replaced by IgG isotopes. DAPI staining of the OLCs was performed in 5\% DAPI-PBS for 5 minutes followed by two washes in PBS.

\subsection{Histology and Immunohistochemistry Staining. Histology} of the colonies was performed after mechanically detaching of whole MEF layer including the ovarian cell colonies from the cell culture well. After detachment, the randomly arranged MEF layer was fixed in Bouin's solution for 3 hours, washed several times for at least $24 \mathrm{~h}$ in $70 \% \mathrm{EtOH}$, and then embedded in paraffin wax. The resulting cell culture conglomerate was randomly sectioned. Due to the large number of colonies sufficient sections of ovarian cell colonies in different orientations were available for histological analysis. Immunohistochemistry was performed as described recently [18] using the following primary antibodies: OCT4A (\#2890S, Cell Signaling Technology, Germany; 1:100), LIN28A (\#3978S, Cell Signaling Technology; $1: 100-1: 200$ ), SALL4 (\#ab57577, Abcam, UK; 1:200), and VASA (DDX4; \#AF2030, R\&D Systems, Germany; $1: 100)$.

2.8. Western Blot Analysis. Western blotting was performed according to standard procedures. In brief, $20 \mathrm{mg}$ of frozen tissue per sample was used. Proteins were isolated by mechanical destruction of the tissue in a TissueLyser at $50 \mathrm{HZ}$ (Qiagen, Hilden, Germany). The samples were denatured for 5 minutes at $95^{\circ} \mathrm{C}$. Samples were then run on a $10 \%$ SDSpage gel in Tris $\mathrm{HCl}$ buffer, $\mathrm{pH} 8.8$, and then semi-dryblotted onto a PVDF membrane (150 mA for $1 \mathrm{~h}$ ). Blocking of unspecific binding was achieved by incubating the membrane in $5 \%$ skim milk powder diluted in TBS for $1 \mathrm{~h}$. Primary antibodies against VASA (\#AF2030, R\&D Systems; $1: 2000$ ) and $\beta$-actin (Santa Cruz, SC-1616-R; 1:5000) were diluted in blocking buffer. Membranes were incubated in primary antibody solutions for 16 hours at $4^{\circ} \mathrm{C}$ and then washed three times with blocking solution supplemented with Tween 20. After incubation with the horseradish peroxidasecoupled secondary antibody $\left(1 \mathrm{~h}\right.$ at $\left.20^{\circ} \mathrm{C}\right)$ the membrane was washed again. Detection of bound antibody was performed using the Amersham ECL Western Blotting Detection Reagents Kit (RPN2106). Signals were detected and documented using the ChemoCam Imager (INTAS, Göttingen, Germany).

2.9. Transcriptome Analysis. For transcriptome analysis, two neonatal marmoset ovaries, colonies from $\mathrm{P} 4$ from two different individual animals (100-300 colonies per sample), marmoset skin fibroblasts, and marmoset ES cells were analyzed. Primary fibroblasts were obtained and cultured as described recently [21]. RNA was isolated using the TRIzol Reagent (Life Technologies) according to the manufacturer's instructions. RNA quality was assessed by measuring the RIN (RNA Integrity Number) using an Agilent 2100 Bioanalyzer (Agilent Technologies, Palo Alto, CA). Library preparation for RNA-Seq was performed by using the TruSeq RNA Sample Preparation Kit (Illumina, Cat. number RS-122-2002) starting from $500 \mathrm{ng}$ of total RNA. Accurate quantitation of cDNA libraries was performed by using the QuantiFluor dsDNA System (Promega). The size range of final cDNA libraries was determined applying the DNA 1000 chip on the Bioanalyzer 2100 from Agilent (280 bp). cDNA libraries were amplified and sequenced by using the cBot and HiSeq2000 from Illumina (SR; $1 \times 50 \mathrm{bp}$; 5-6 GB ca. 30-35 million reads per sample). Sequence images were transformed with Illumina software BaseCaller to bcl files, which were demultiplexed to fastq files with CASAVA v1.8.2. Quality check was done via fastqc (v. 0.10.0, Babraham Bioinformatics). The alignment was performed using Bowtie2 v2.1.0 to the cDNA for Callithrix jacchus. Data were converted and sorted by samtools 0.1 .19 and reads per gene were counted via htseq version 0.5.4.p3. Data analysis was performed by using R/Bioconductor (3.0.2/2.12) loading DESeq, gplots, and goseq packages. Candidate genes were filtered to a minimum of $4 \mathrm{x}$ fold change and FDR-corrected $p$ value $<0.05$. The data discussed in this paper were generated in compliance with the MIAME guidelines and have been deposited in NCBI's Gene Expression Omnibus and are accessible through GEO Series accession number GSE 64966.

\subsection{Quantitative Reverse Transcriptase Polymerase Chain} Reaction (RT-qPCR) Analysis. RT-qPCR was carried out as described previously [18]. Total RNA was extracted from different passages of colony-forming cells. Around 50-100 colonies per passage were pooled and analyzed. Three independent cultures (derived from three different animals) were analyzed. Each RNA sample was analyzed in triplicate. As positive controls, neonatal marmoset ovary and marmoset embryonic stem cells were used. Marmoset monkey fibroblasts served as a biological negative control for pluripotency and germ cell markers. Primers are listed in Supplementary Table 1 in Supplementary Material available online at http://dx.doi.org/10.1155/2016/2480298. For oocytelike cell RNA extractions, altogether 28 cells from different 
TABLE 1: Primer sequences, sizes of amplicons, and concentration of respective primers.

\begin{tabular}{|c|c|c|c|}
\hline Primer & Primer sequence & PCR product size $(\mathrm{bp})$ & Concentration $[\mathrm{nM}]$ \\
\hline Cj_GAPDH_Fw & $5^{\prime}$-TGCTGGCGCTGAGTATGTG-3' & 64 & 300 \\
\hline Cj_GAPDH_Re & $5^{\prime}$-AGCCCCAGCCTTCTCCAT-3' & & 50 \\
\hline $\mathrm{Cj} L I N 28 \_F w$ & $5^{\prime}$-GACGTCTTTGTGCACCAGAGTAA-3' & 67 & 300 \\
\hline $\mathrm{Cj} L L I N 28 \_\mathrm{Re}$ & 5'-CGGCCTCACCTTCCTTCAA-3' & & 50 \\
\hline Cj_SALL4_Fw & $5^{\prime}$-AAGGCAACTTGAAGGTTCACTACA-3' & 77 & 900 \\
\hline $\mathrm{Cj} \_S A L L 4 \_\mathrm{Re}$ & $5^{\prime}$-GATGGCCAGCTTCCTTCCA-3' & & 50 \\
\hline $\mathrm{Cj}_{-} V A S A \_\mathrm{Fw}$ & $5^{\prime}$-TGGACATGATGCACCACCAGCA-3' & 210 & 50 \\
\hline $\mathrm{Cj}_{-} V A S A \_\mathrm{Re}$ & $5^{\prime}$-TGGGCCAAAATTGGCAGGAGAAA-3' & & 900 \\
\hline Cj_OCT4A_Fw & $5^{\prime}$-GGAACAAAACACGGAGGAGTC-3' & 234 & 300 \\
\hline Cj_OCT4A_Re & 5'-CAGGGTGATCCTCTTCTGCTTC-3' & & 50 \\
\hline $\mathrm{Cj} P R D M 1 \_\mathrm{Fw}$ & 5'-ATGAAGTTGCCTCCCAGCAA-3' & 147 & 50 \\
\hline $\mathrm{Cj} \_P R D M 1 \_\mathrm{Re}$ & $5^{\prime}$-TTCCTACAGGCACCCTGACT-3' & & 50 \\
\hline Cj_PRDM14_Fw & $5^{\prime}$-CGGGGAGAAGCCCTTCAAAT-3' & 91 & 50 \\
\hline $\mathrm{Cj} P R D M 14 \_\mathrm{Re}$ & $5^{\prime}$-CTCCTTGTGTGAACGTCGGA-3' & & 50 \\
\hline $\mathrm{Cj} D A Z L \_F w$ & $5^{\prime}$-GAAGAAGTCGGGCAGTGCTT-3' & 70 & 50 \\
\hline Cj_DAZL_Re & $5^{\prime}$-AACGAGCAACTTCCCATGAA-3' & & 50 \\
\hline $\mathrm{Cj} \_D P P A 3 \_\mathrm{Fw}$ & $5^{\prime}$-GCGGATGGGATCCTTCTGAG-3' & 129 & 50 \\
\hline $\mathrm{Cj} D P P A 3 \_\mathrm{Re}$ & $5^{\prime}$-GAGTAGCTTTCTCGGTCTGCT-3' & & 50 \\
\hline $\mathrm{C} \mathrm{j} \perp O B O X \_\mathrm{Fw}$ & 5'-GAAGACCACTATCCTGACAGTG-3' & 320 & 50 \\
\hline $\mathrm{C} \_N O B O X \_\mathrm{Re}$ & $5^{\prime}$-TCAGAAGTCAGCAGCATGGGG-3' & & 50 \\
\hline Cj_SCP3_Fw & $5^{\prime}$-TGGAAAACACAACAAGATCA-3' & 60 & 50 \\
\hline Cj_SCP3_Re & $5^{\prime}$-GCTATCTCTTGCTGCTGAGT-3' & & 50 \\
\hline
\end{tabular}

passages were collected and randomly divided into two groups. The RNA was isolated with the RNeasy MICRO kit (Qiagen) according to the manufacturer's instructions. To analyze the relative gene expression level changes during the culture within one passage, colonies from P7 were seeded into 8 separate wells. The cells from two wells were harvested for analysis at days 2, 4, 6, and 8. Primer sequences, sizes of PCR products and primer concentrations are given in Table 1.

2.11. Hormone Measurements. Measurement of progesterone in the selected cell culture medium samples after at least 3 days of conditioning was performed using an enzyme immunoassay (EIA) using antiserum raised in sheep against progesterone-11-hemisuccinate-BSA as described by Heistermann and colleagues [22]. Fresh medium was used as control. Estradiol-17 $\beta$ was determined using an EIA according to Heistermann et al. [23] with the exception that $17 \beta$-estradiol6-horse-radish-peroxidase was used as label. Both steroid measurements were performed in undiluted samples and fresh medium was used as control.

2.12. Cell Transplantation Assay. In order to test the cultured ovarian cells for their regenerative and tissue neomorphogenesis potential, we subcutaneously injected $\sim 10^{6}$ cells per mouse. The cells were obtained from Accutase-treated ovarian cell colonies from the 5 th passage. Four female adult $\mathrm{RAG}^{-/-} \gamma \mathrm{c}^{-/-}$mice lacking $\mathrm{B}, \mathrm{T}$, and NK cells were used. The technical procedure has been described previously for neonatal testis tissue [24].

\section{Results}

3.1. General Observations and Morphology of the Primary Cell Cultures. We established a long-term primary culture of ovarian cells. This included passaging as well as expansion of the cells. Five individual primary cultures of neonatal marmoset ovaries were performed and run up to 6 months with very similar morphology and kinetics. The maximum passage number was 23 . Then the cells stopped proliferation. Initially, relatively small ovarian cell colonies (OCCs) formed which could be distinguished from the MEFs by the morphology of the cells and the colonies' boundaries (Figure 1(a)). The OCCs quickly increased in size forming big colonies with diameters up to $1000 \mu \mathrm{m}$ (Figure 1(b)) within a few days. The cells forming the OCCs exhibited an epitheloid phenotype as judged from morphology (Figure 1(d)); that is, they are apparently polar with apical nuclei, and no intracellular matrix was visible between the cells forming the colonies by light microscopy. However, the cells lacked typical epithelial markers such as E-cadherin (CDH1). For further details, see below. In higher passages the individual OCCs became smaller (compare Figures 1(b) and 1(c)). Some OCCs developed in their centers a second layer of cells on top of the primary cell layer (Figure 1(c)). The morphology of the colonies was faintly reminiscent of primate ES cell colonies [20] (Figure 1(e)). Colonies with the morphology of OCCs were never observed in pure mouse embryonic feeder cell cultures.

3.2. OCCs Lack a Germ Cell Population in Early Passages. In order to initially compare the neonatal ovary-derived cell 


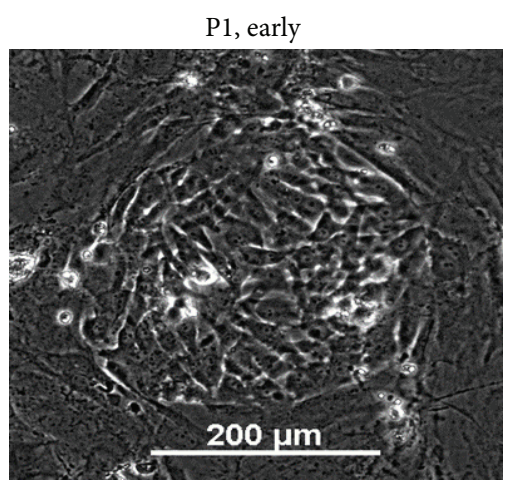

(a)

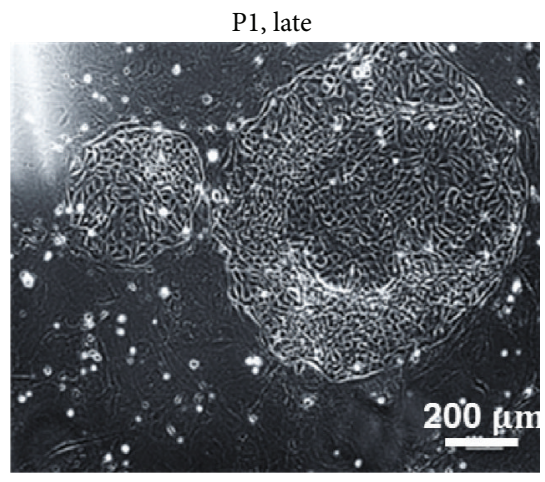

(b)

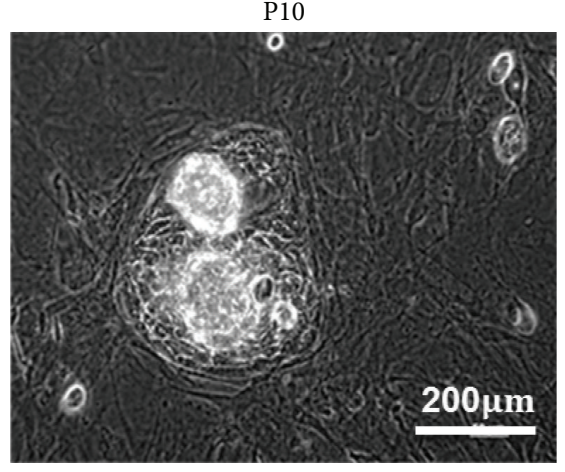

(c)

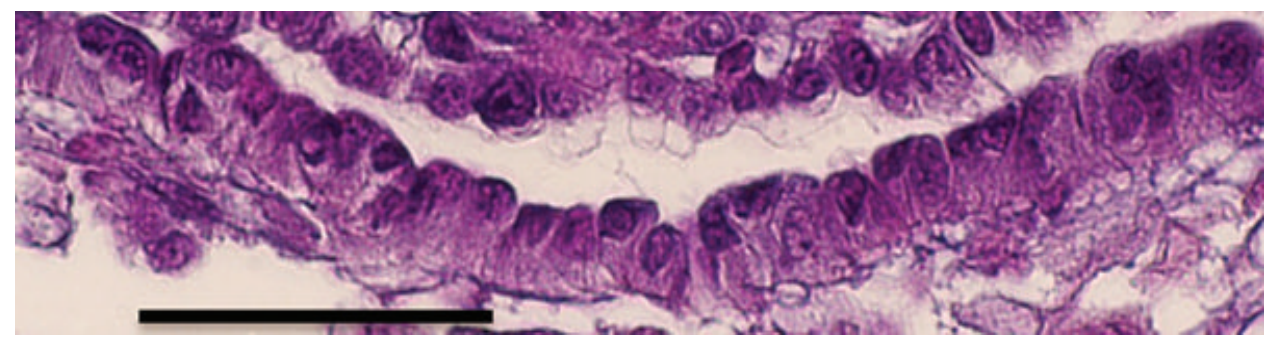

(d)

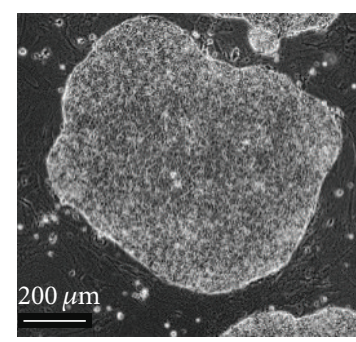

(e)

Figure 1: Morphology of ovarian cell colonies (OCCs). (a-c) Morphology of cell colonies in the first passage and in higher passages. (d) H\&E staining of cross sections of colonies. Cells have an epitheloid morphology with rather apical nuclei. (e) Morphology of a marmoset monkey ES cell colony.

colonies on the transcriptome level with reference samples we performed a comprehensive transcriptome analysis of OCCs by deep sequencing and compared the data set with the transcriptomes of neonatal ovaries, which served as starting material and contained oogonia, marmoset ES cells as a reference for pluripotent cells, and skin fibroblasts, which represent prototypic mesenchymal cells. Each individual sample's transcriptome was represented by at least 12 Mio. reads (Supplementary Figure 1). About 40.000 different transcripts were detected in each individual sample (Supplementary Figure 2). We used low passage number samples (passage 4) in order to obtain data from cells without extensive cell culture adaptation artefacts. Due to the very limited material, only two independent OCC samples and two neonatal ovaries could be analyzed. However, already this small set of samples provided valuable insights (Figure 2). The OCC samples were clearly distinct from native ovary and fibroblasts (Figure 2(a)). In contrast, the differences between the OCCs' and the ES cells' transcriptomes were smaller. Importantly, the PCA plot (Figure 2(a)) indicates fundamental differences between the transcriptomes of ovaries and OCCs. Notably, the top 50 differentially expressed genes between native ovaries and OCCs revealed two major facts (Figure 2(b)). (1) Almost all differentially expressed genes were overrepresented in the native ovary. This suggests that the OCCs generally represent a subpopulation of the whole cell population constituting the native ovary and that no completely different or novel cell type developed in culture, at least not in detectable quantities. (2) Among the top 50 differentially expressed genes are numerous germ-cellspecific genes like MAEL, RNF17, TEX12, TDRD9, MOV10L1,
NOBOX, ZP3, FIGLA, SOHLH2, DAZL, and SYCP2. In fact, several germ cell genes, including DAZL, MAEL, RNF17, TEX12, TEX101, and TDRD, were totally undetectable in the transcriptomes of the OCCs. Other transcripts like OCT4, LIN28, and VASA were also extremely low or absent. This strongly indicates the complete loss of the typical neonatal ovarian germ cell population, including postmigratory PGCs, oogonia, and oocytes in the cell culture.

The comparison between the OCCs and the fibroblasts revealed an increased expression of many genes in the OCCs (Figure 2(c)). The upregulated genes include COL2A1, the keratin gene KRT36, and VCAM1. Importantly, however, no germ cell gene was found upregulated in OCCs compared to fibroblasts, further substantiating the absence of germ cells from the OCC cultures. The comparison of the top 50 differentially expressed genes between the OCCs and the ES cells showed that most genes were upregulated in ES cells, like TDGF1, LIN28A, OCT4 (POU5F1), and NANOG. Only a few genes including the dual specificity phosphatase 13 (DUSP13) and the serine peptidase inhibitor, Kazal type 1 (SPINK1), were upregulated in OCCs (Figure 2(d)).

The detailed cellular identity of the OCCs could not be determined so far. Many of the cells of the OCCs were proliferation marker Ki-67-positive (Supplemental Figure S3). Although the cells had an epitheloid shape, we failed to detect E-cadherin in the transcriptome data as well as by IHC (data not shown). Also cytokeratins as characteristic proteins of epithelial cells were only barely represented in the transcriptomes. Vimentin as typical protein of cells of mesenchymal origin was expressed at medium levels ( $50 \%$ of neonatal ovary levels and $30 \%$ of fibroblast levels). However, 


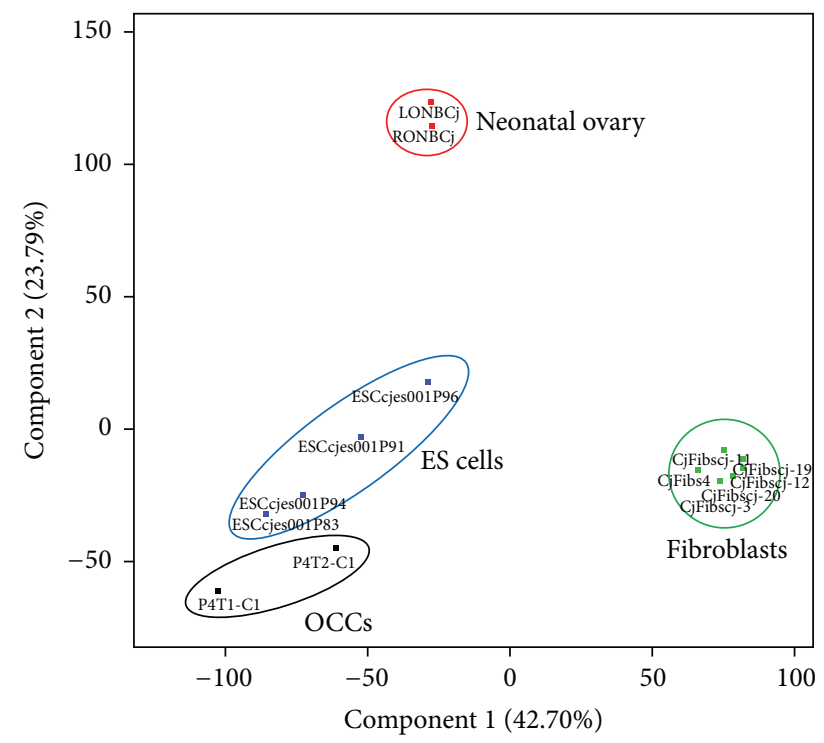

(a)

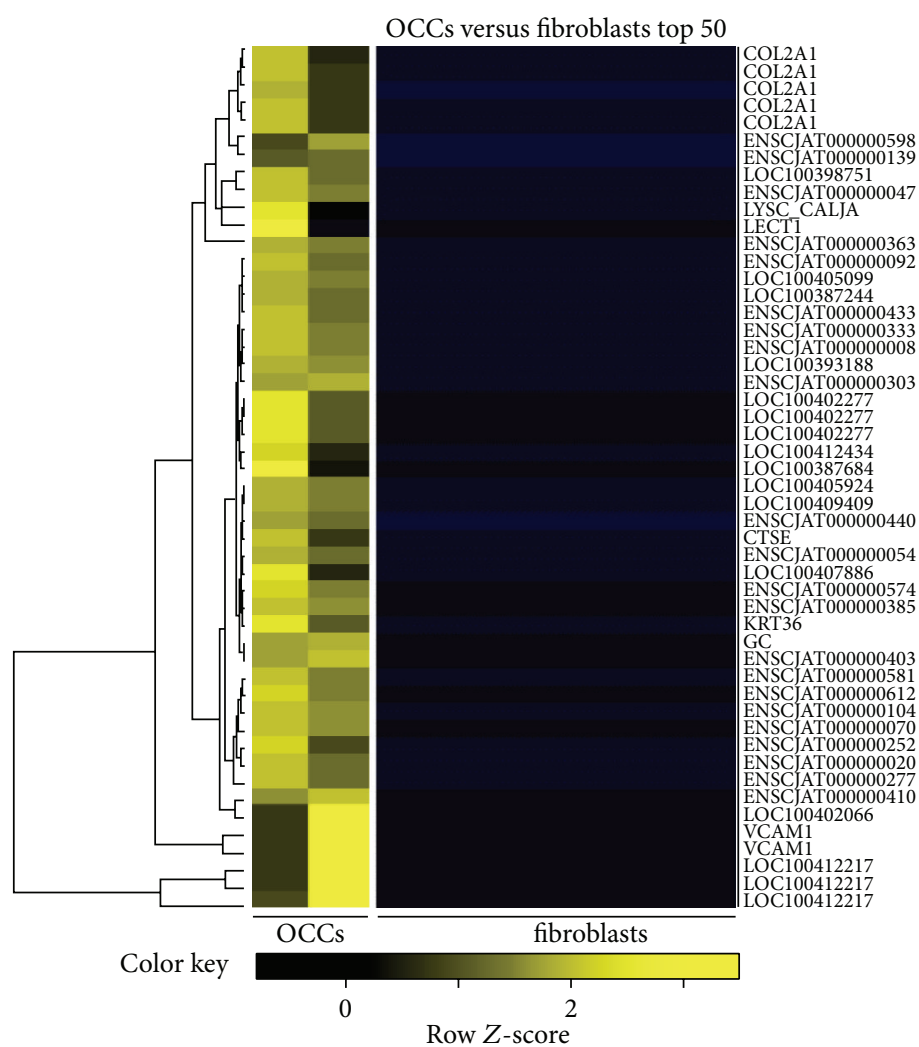

(c)

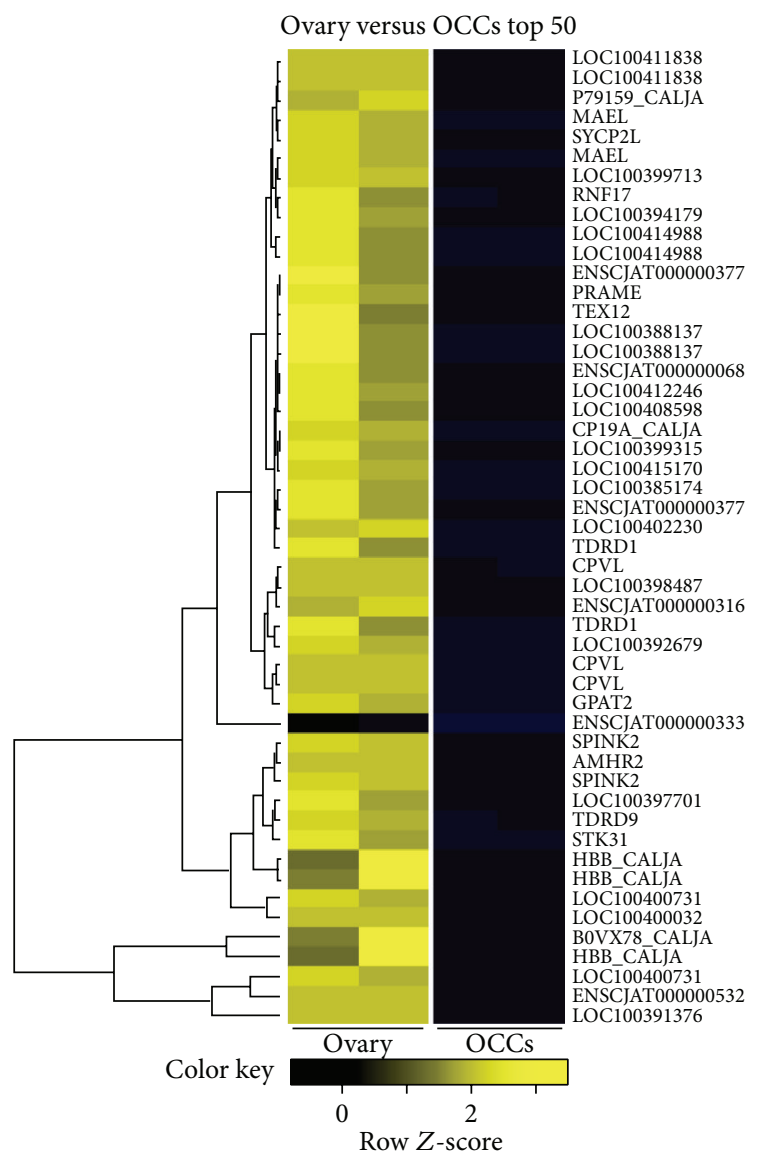

(b)

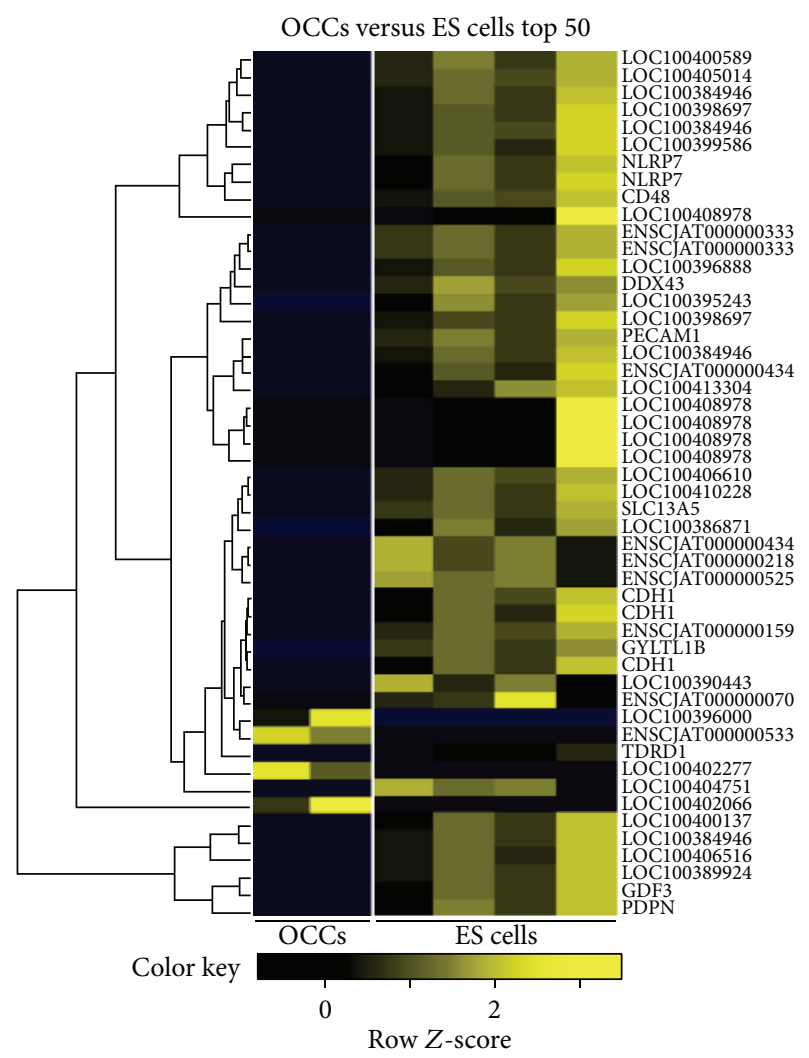

(d)

Figure 2: Continued. 


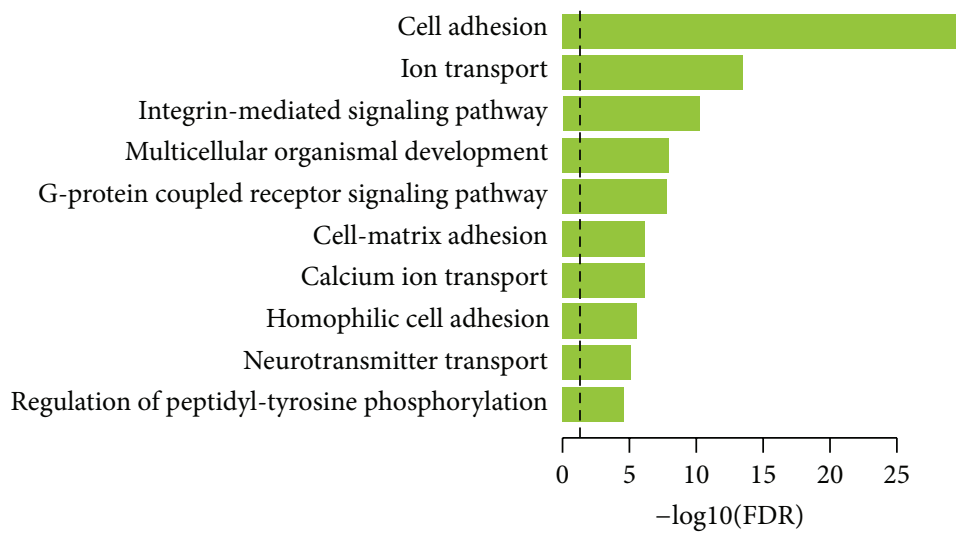

(e)

Figure 2: Transcriptome analysis of OCCs. (a) Principal component analysis of the transcriptome analyses of ovarian cell colonies (OCCs), neonatal ovaries, which served as starting material for OCC cultures, embryonic stem cells, and fibroblasts. The latter two served as reference samples. OCC transcriptomes differ from the neonatal ovaries' transcriptomes. However, ovaries, ES cells, and OCCs are more similar among each other than to fibroblasts (see component 1, relative weight of 38.54\%). (b) Top 50 differentially expressed genes between native neonatal ovary and OCCs. For gene bank and Ensembl identifiers, see Table 1 of Supplementary Material. (c) Top 50 differentially expressed genes between OCCs and fibroblasts. (d) Top 50 differentially expressed genes between OCCs and ES cells. (e) Gene ontology analysis of OCCs versus native ovary. Cell adhesion, ion and neurotransmitter transporters, and signaling pathways are predominantly upregulated in OCCs compared to the native ovary.

other cadherins such as $\mathrm{CDH} 2$ (at similar levels in cultured ovarian cells compared to ovaries, fibroblasts, and ES cells) and $\mathrm{CDH}_{2} 2$ (the same range as neonatal ovaries, $10-20 \%$ of fibroblasts, and $50 \%$ of ES cells) were expressed by the OCCs. Hence, the phenotypical and molecular indicators of the status of the cells constituting the OCCs are not congruent. In order to initially characterize the features of the OCCs we performed a gene ontology analysis based on the genes upregulated in OCCs compared to native ovary (Figure 2(e)). This shows that particularly cell adhesion, ion and neurotransmitter transport, and signaling pathways are upregulated in the OCCs.

In summary, the transcriptome data indicate that germ cells are absent from the OCCs. However, the detailed identity of the OCCs remains unclear so far. Due to the limited number of samples $(n=2)$ and the fact that we could analyze only one time point by deep sequencing, we further investigated specific genes by RT-qPCR in different passages to obtain also longitudinal data over the course of the OCC culture.

We have recently shown that the neonatal marmoset monkey ovary contains primitive proliferating germ cells expressing the germ cell and pluripotency markers OCT4A, SALL4, LIN28, and the general germ cell marker VASA (DDX4) [18]. All these markers are only very poorly represented in the transcriptomes of the early passage OCCs or were even absent. We also failed to detect OCT4A, LIN28, or VASA on the protein level in early passage OCC samples by a well-established immunohistochemistry protocol [18] (data not shown). In order to quantify the expression of selected key marker genes in OCCs in relation to ES cells, skin fibroblasts, and neonatal ovaries by an independent method and also at higher $(>4)$ passages, we performed RTqPCR for a number of pluripotency and (premeiotic) germ cell markers including OCT4A [25], NANOG [25], SALL4 [26], LIN28 [27], VASA [28, see also Figure 5], DAZL [29], NOBOX [30], DPPA3/STELLA/PGC7 [31, 32], PRDM1 [33], and PRDM14 [34, 35]. Figure 3 shows the exemplary RTqPCR data of one culture from passage 1 to passage 13 . These data confirm that the most indicative pluripotency factors OCT4A and NANOG were not expressed in all OCC samples analyzed (Figure 3). In contrast, SALL4, LIN28, and $V A S A$ were induced in passages $\geq \mathrm{P} 4$ except for SALL4 and LIN28 in P9. In order to further substantiate these findings, we also tested the expression of PRDM1, PRDM14, DAZL, $D P P A 3, N O B O X$, and SCP3 in the OCCs from different passages (Figure 4). DAZL, DPPA3, NOBOX, and SCP3 as specific germ cell genes were absent or very low at low passages, which is in concordance with the data shown in Figure 3. In later stages, however, all markers were detectable at variable levels. In contrast, PRDM1 and PRDM14, early germ cell specification genes but not specific to germ cells, were robustly expressed in all cell culture samples. These data suggest that our culture supports the survival and probably also the selection of cells that have the potential to (re)express a set of premeiotic and female germ cell marker genes.

3.3. The OCCs Generate Oocyte-Like Cells. OCCs generated large, free-floating spherical cells, which we termed oocytelike cells (OLCs; [17]). OLCs had a morphology resembling immature oocytes. Their diameter ranged from 20 to $\sim 40 \mu \mathrm{m}$ (Figure 5(a)). We sometimes also observed small structures slightly resembling polar bodies (Figure 5(a), right picture). However, we never observed Zona pellucida nor folliclelike structures as described by Dyce et al. [17]. For comparison of the OLCs with real marmoset monkey oocytes, see Figure 5(b). Importantly, OLCs developed even after 20 


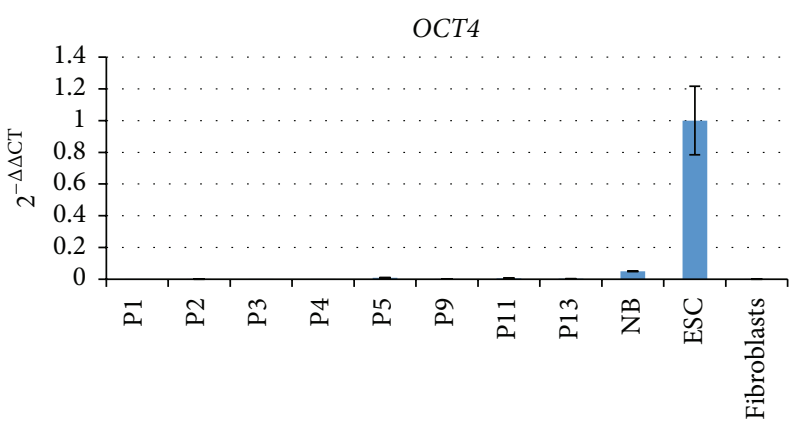

(a)

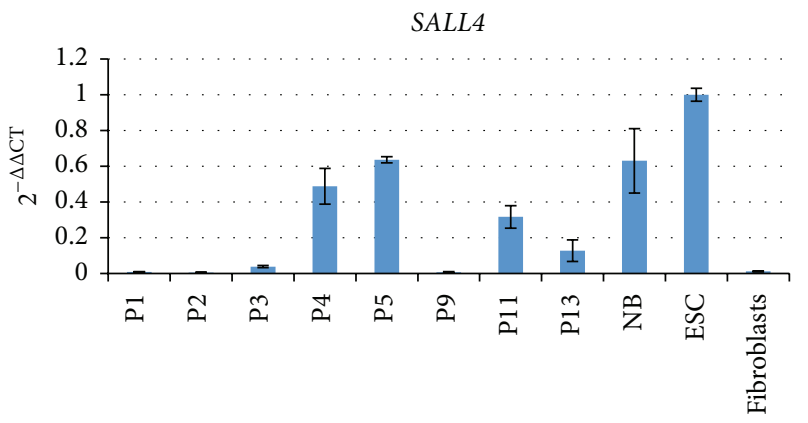

(c)

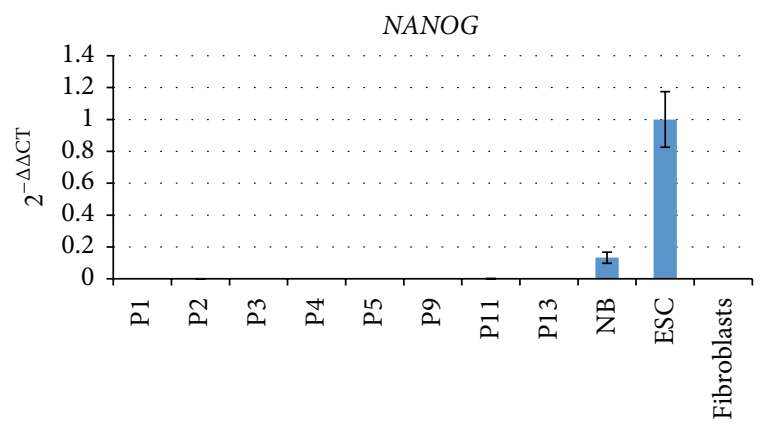

(b)

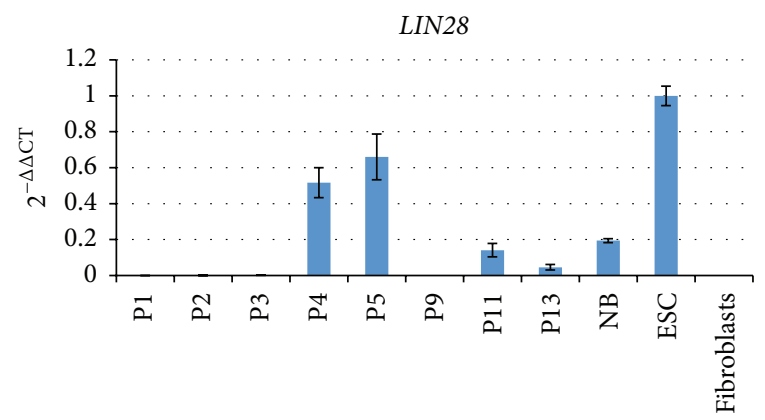

(d)

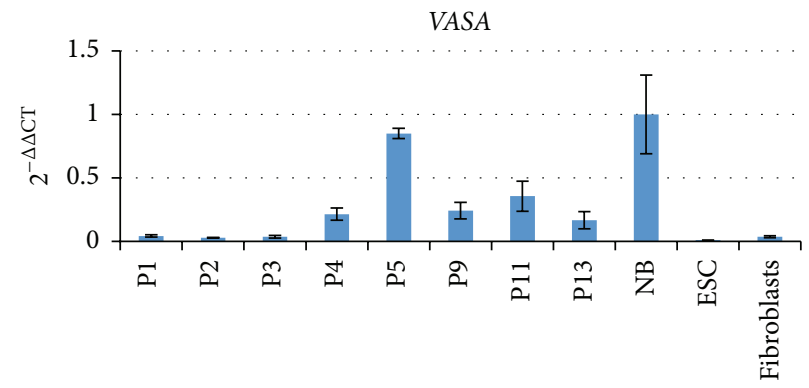

(e)

FIGURE 3: RT-qPCR analysis of OCCs in different passages. Real-time quantitative RT-PCR analysis of selected key pluripotency and germ cell markers in OCCs. OCT4, NANOG, SALL4, and LIN28 are all robustly expressed in pluripotent stem cells as well as in primitive germ cells. In contrast OCT4 and NANOG are absent from OCCs. SALL4 and LIN28 were absent or very low at low passages and increased in expression at higher passages. VASA is a general germ cell marker and was detected in later OCC passages and in the neonatal ovary.

passages and more than 5 months of culture but were not observed in passages $<4$. We also observed OLCs neither in MEF-only cell cultures nor in ESC cultures which are also based on MEFs. This strongly indicates that the OLCs indeed derive from the OCCs. To initially characterize the OLCs, we tested the expression of key pluripotency and germ cell markers by RT-qPCR. We collected 28 OLCs and randomly allocated the cells to one of two groups (termed OLCs1 and OLCs2), which were then analyzed. OCT4A, NANOG, and LIN28 were low in OLCs compared to ES cells and neonatal ovaries (Figures 5(c)-5(e)). SALL4 was robustly expressed (Figure 5(f)) in the range of the controls. In contrast, PRDM14, DPPA3, DAZL, and VASA were much higher in OLCs than in neonatal ovary indicating very robust expression of these germ cell markers in OLCs (Figures 5(g)$5(\mathrm{j}))$. NOBOX was in a similar range as in the neonatal ovary. Importantly, $D A Z L, V A S A$, and $N O B O X$ are specific germ line markers and are all not expressed by ES cells and fibroblasts (Figures 5(i)-5(k)). As a marker of meiosis, we also tested SCP3. This mRNA was also detected in OLCs, although at lower levels compared to the neonatal ovary (Figure 5(1)). SCP3 was undetectable in ES cells and fibroblasts. A good indicator of meiosis is chromatin condensation in preparation of the reduction division (Figure 5(m), left). However, we did not see a comparable chromatin condensation in OLCs. In contrast, the OLCs showed a homogenous DAPI signal throughout the nucleus (Figure 5(m), right). Although there was no evidence for meiosis, the expression of the markers strongly indicates a germ cell identity of the OLCs. In order to further corroborate the germ line identity of the OLCs we aimed at detecting also VASA protein in the OLCs. First we characterized the VASA antibody to prevent misleading antibody-based results as we [36] and others [37] recently described. In western blot analysis a 


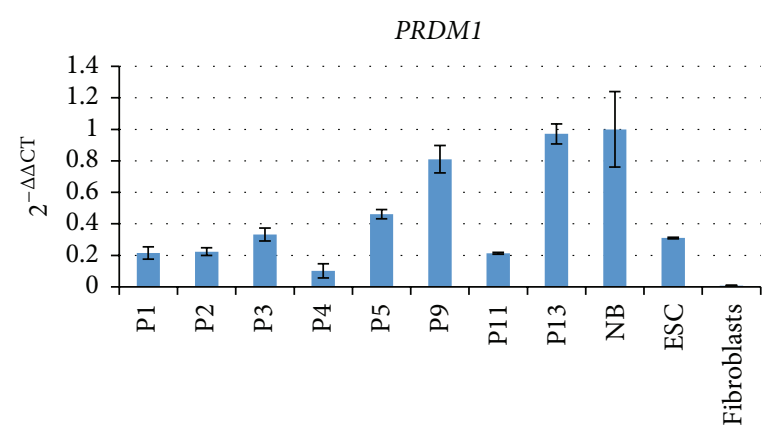

(a)

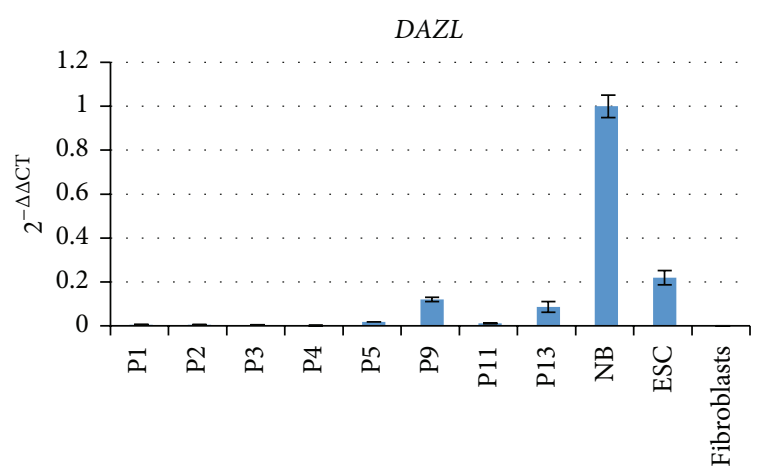

(c)

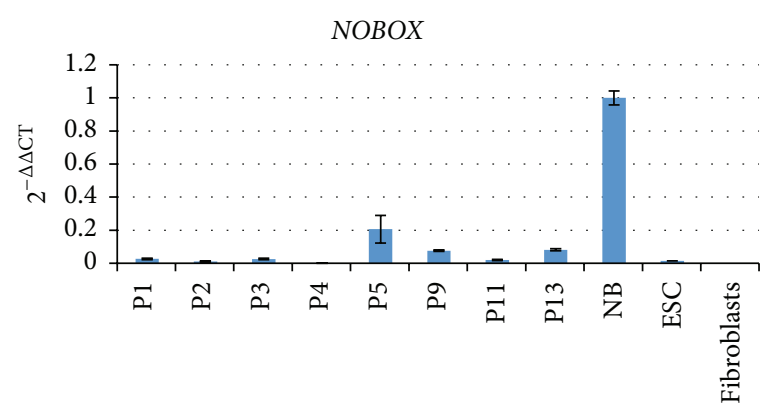

(e)

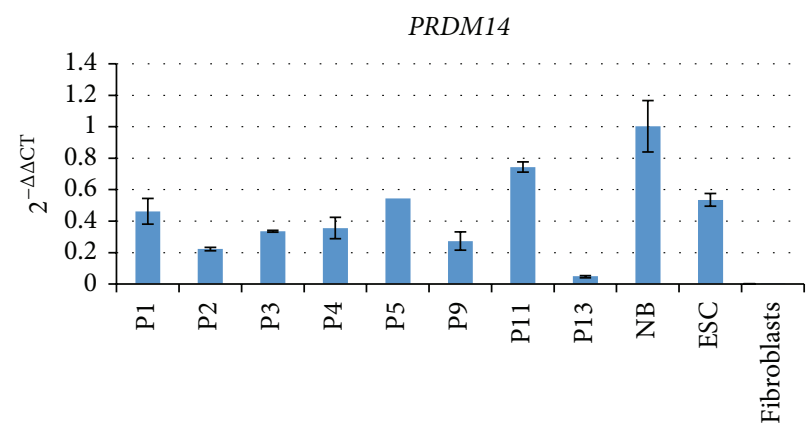

(b)

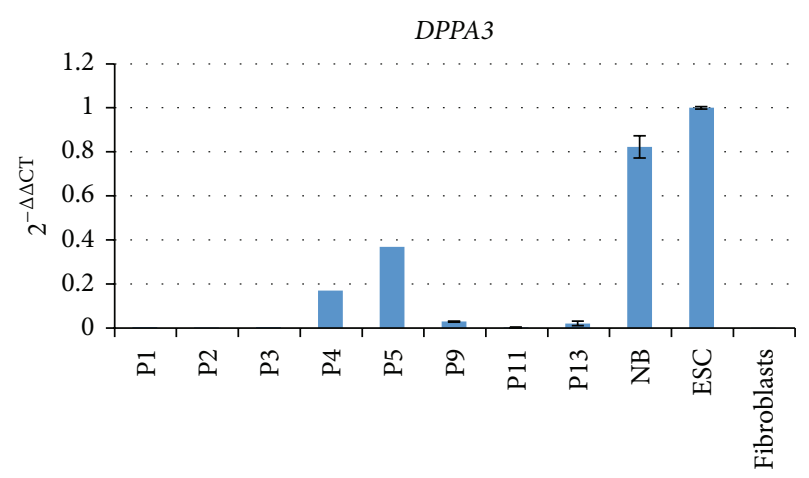

(d)

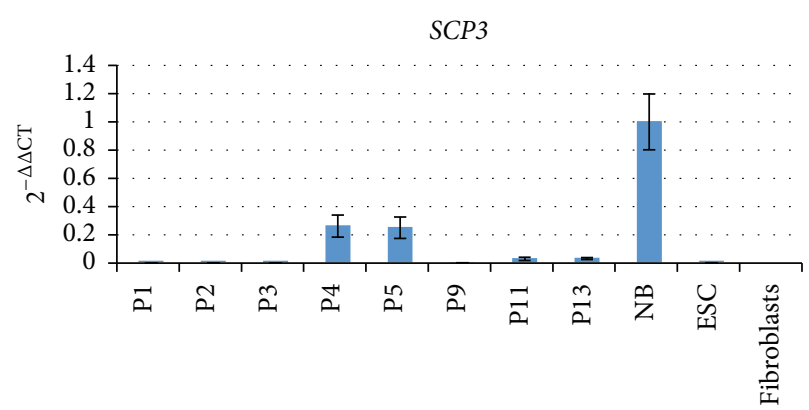

(f)

FIgURE 4: Expression of additional germ cell markers in OCCs. PRDM1 and PRDM14 are necessary for germ cell specification and are expressed in all OCC passages in the range of the controls. DAZL and DPPA3 are also necessary for germ cell specification and were detectable only in few samples. NOBOX is a female-specific germ cell marker and was detectable at relatively low levels in most samples. SCP3 is a meiosis marker and was detectable only in some samples at variable levels. In general, the germ-cell-specific markers were very low or absent during the first three passages.

very intense and prominent band of the expected size of $\sim 85 \mathrm{kDa}$ was detected in testis indicating a high specificity of the VASA antibody (Figure 6(a)). Lack of a VASA signal in the ovary was due to the fact that the ovary was from an old monkey with an almost exhausted ovarian germ cell reserve. Hence, VASA was below the detection limit in the protein homogenate of the aged ovary. We also tested the VASA antibody in immunohistochemistry on tissue sections from adult marmoset testis and ovary (Figures 6(b) and 6(c)). In both sexes, the antibody very robustly and specifically detected an epitope in germ cells resulting in clear cytoplasmic germ cell labeling. The nongerm cells were not stained or showed only faint background staining. These findings demonstrate the specificity of the antibody also for marmoset VASA protein. We then used this antibody to detect potential
OLCs in OCCs. When we fixed OCCs of the 5th passage in situ, large cells with strongly condensed chromatin, as indicated by strong DAPI fluorescence in Figure 6(d), were labeled by the VASA antibody (Figure 6(e)). Whether the signal of the surrounding cells is only background staining or whether it highlights small germ cell progenitor cells cannot be decided at present. The diameter of the large labeled cell was approximately $35 \mu \mathrm{m}$ like the diameter of the OLCs shown in Figure 5(a). We also detached the cell cultures from the culture dish and processed them-like the testis and ovary shown in Figures 6(b) and 6(c)-for immunohistochemistry. We detected large isolated cells that were strongly stained for VASA (Figures $6(\mathrm{f})$ and $6(\mathrm{~g})$ ). The control where VASA was replaced by the corresponding IgG showed only very faint background signals (Figure 6(h)). These data demonstrate 

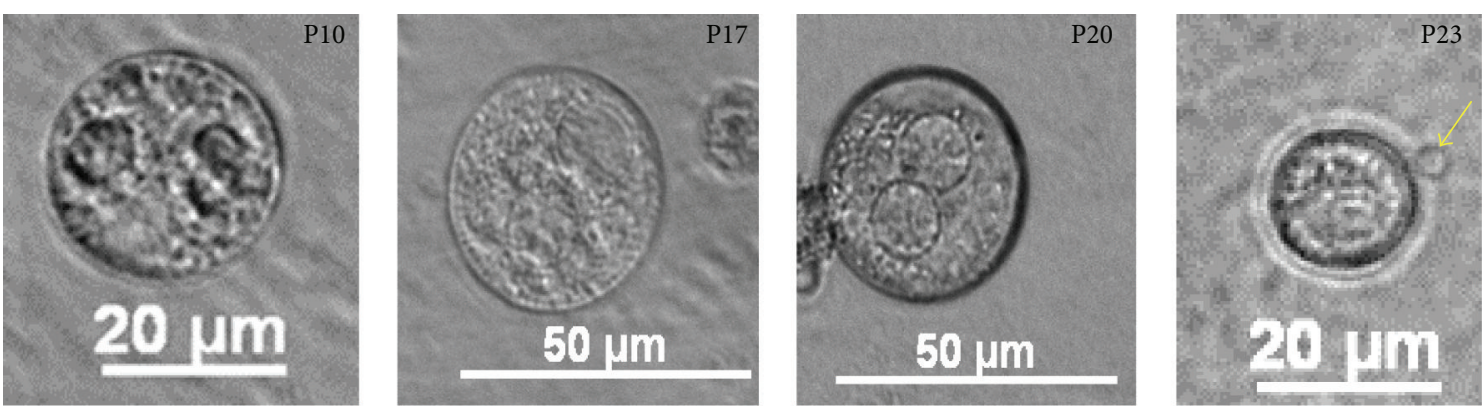

(a)
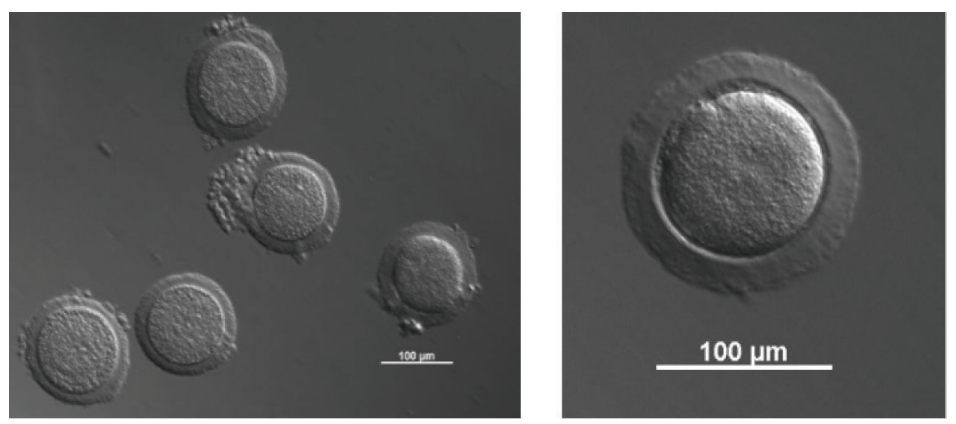

(b)

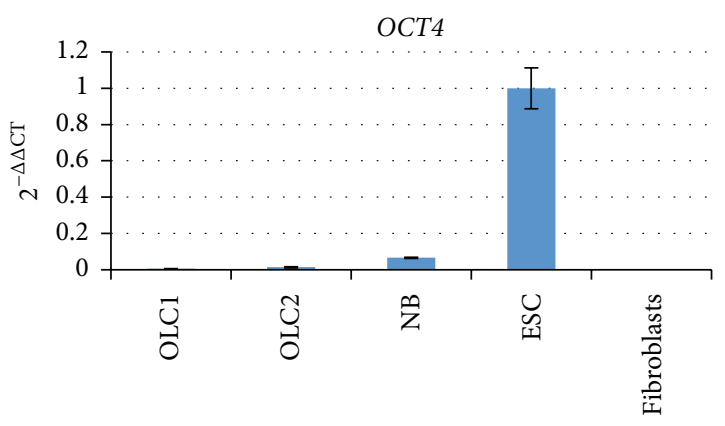

(c)

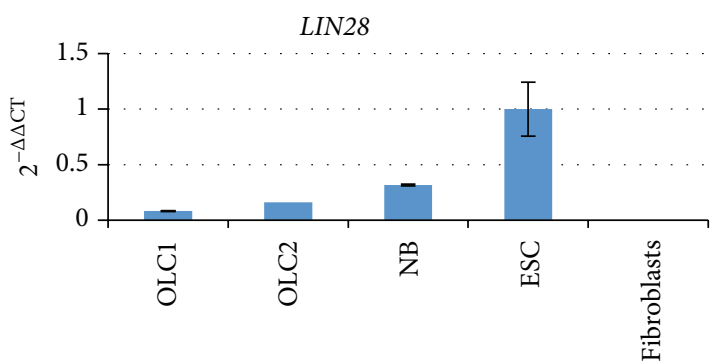

(e)

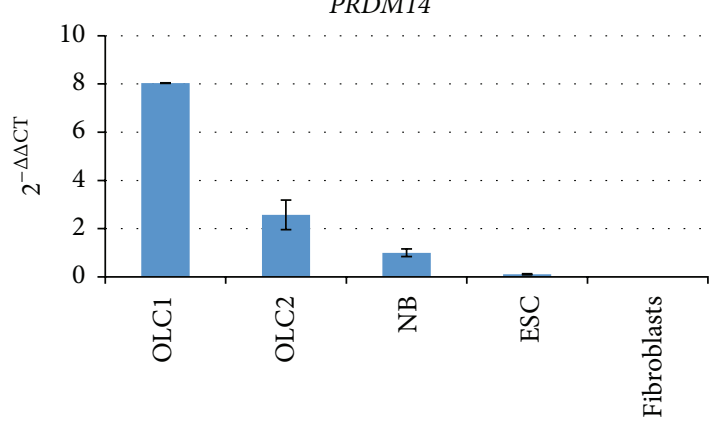

(g)

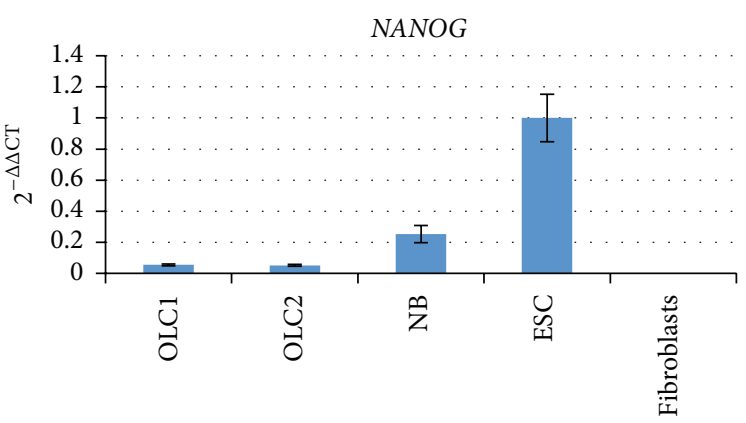

(d)

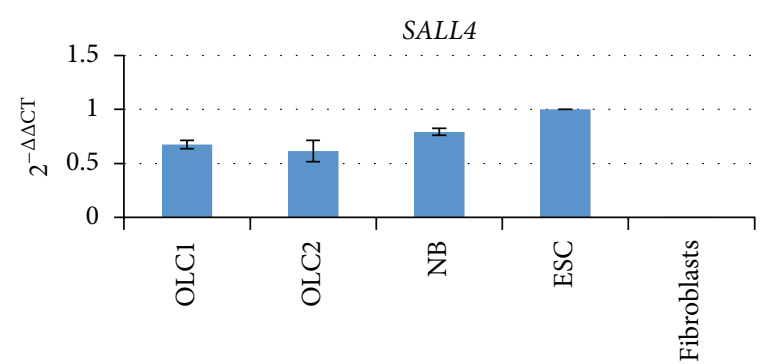

(f)

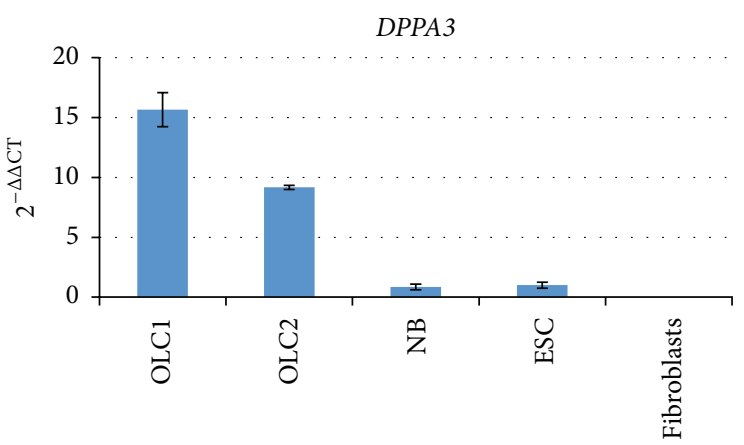

(h)

FIGURE 5: Continued. 


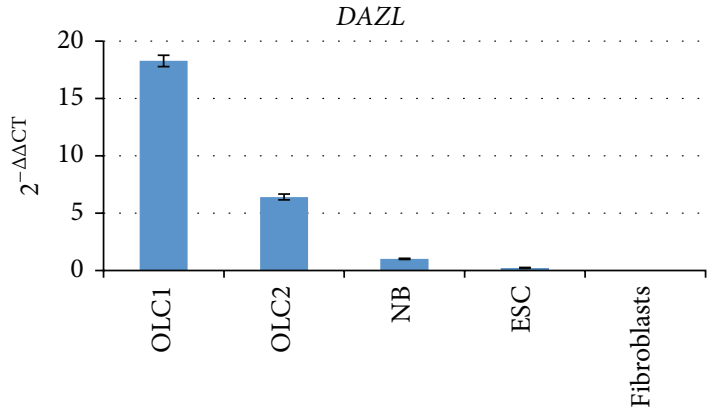

(i)

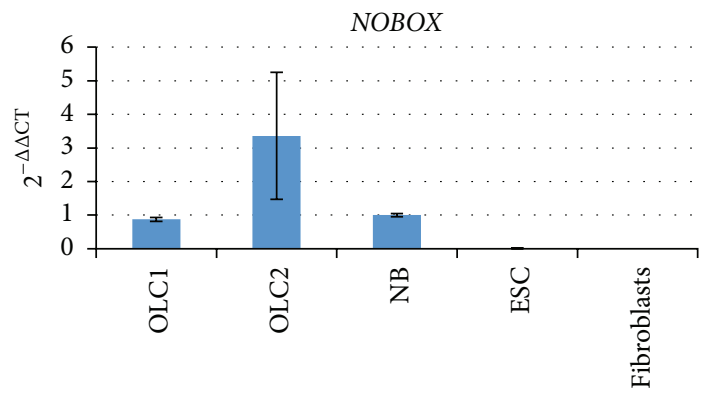

(k)

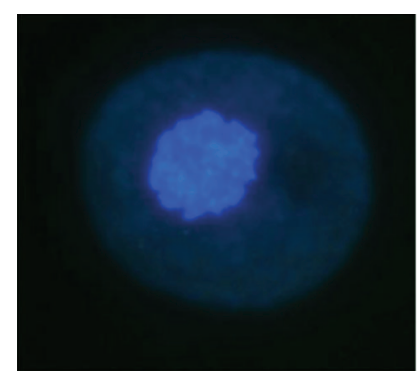

Oocyte/DAPI

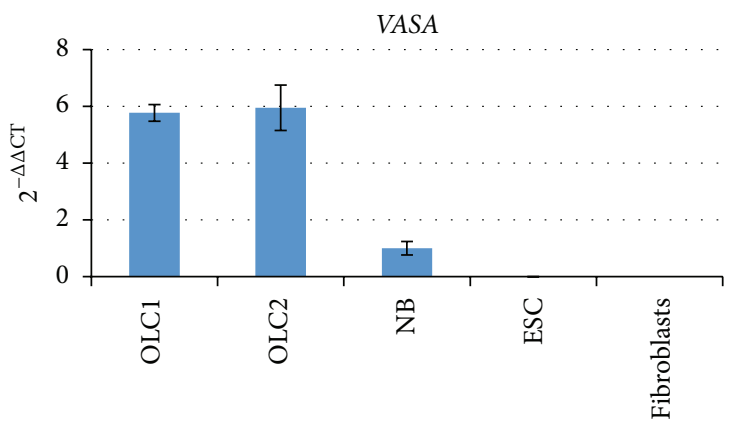

(j)



(l)



OLC/DAPI

(m)

FIGURE 5: Oocyte-like cells derived from OCCs highly express germ cell markers. (a) Oocyte-like cells that spontaneously developed even in high cell culture passages. The cells were freely floating in the cell culture medium and had a diameter of approximately $40 \mu \mathrm{m}$. The passage number is indicated in the upper right corner of each picture. Sometimes small spherical structures attached to the OLCs could be seen slightly resembling polar bodies (arrow). (b) Left: a group of natural marmoset monkey oocytes. Some oocytes are still associated with granulosa cells. Right: higher magnification of a marmoset monkey oocyte with a robust Zona pellucida. (c-l) Oocyte-like cells express pluripotency and germ cell markers. Relative mRNA levels of selected pluripotency and germ cell markers in oocyte-like cells as revealed by real-time quantitative RT-PCR. For OCT4A, SALL4, and LIN28, ES cells were used as positive control. Neonatal ovary was used as positive control for the germ cell markers. Fibroblasts served as biological negative control. (m) DAPI staining of a natural oocyte (left) and of an OLC. While the oocyte shows strongly compacted chromatin, the DAPI staining of the OLC is homogenous indicating a different chromatin state in OLCs and natural oocytes.

that there are isolated VASA protein-positive oocyte-like cells in the cultures derived from neonatal marmoset monkey ovary.

\subsection{The Relative Marker Abundance Is Decreasing within One} Passage. To obtain initial information on the transcript abundance of the markers during the OCC development over time within one passage, we isolated RNA from duplicate samples from OCCs after 2, 4, 6, and 8 days. OCT4A, NANOG, and LIN28 were very low or absent (Figures 7(a)7(c)). In contrast, SALL4 and VASA were robustly detectable in all samples (Figures 7(d) and 7(e)). Both markers exhibited a high abundance at day 2. Later time points (days
4-8) showed a decrease in transcript abundance relative to $G A P D H$ probably reflecting a higher proliferation rate of the marker-negative (but GAPDH expressing) cells compared to the marker-positive cells leading to a dilution effect of the VASA- and SALL4-positive cells.

3.5. No Production of Sex Steroids by the OCCs. We were wondering whether the OCCs have the ability to produce female sex steroids like specific cells of the ovary in vivo. Therefore, we tested medium samples from low and high culture passages after several days without medium change. Samples were analyzed for estradiol, which is primarily produced by ovarian granulosa cells, and progesterone, which 


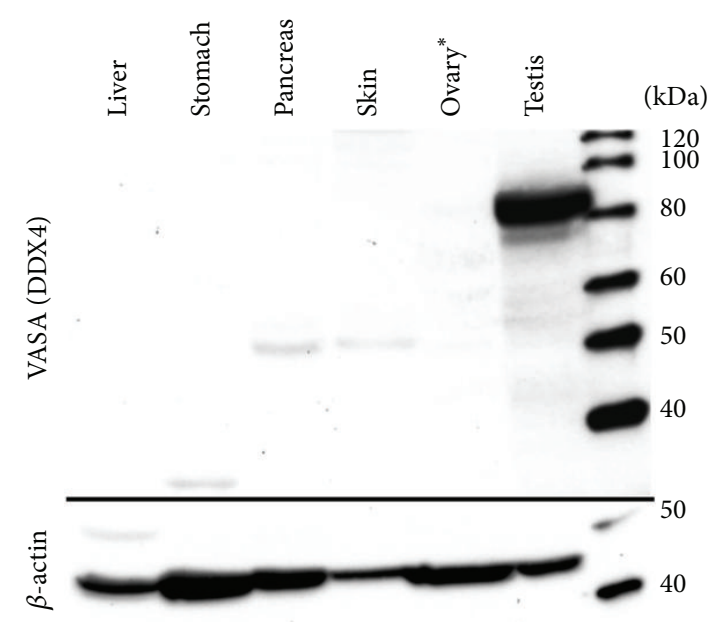

(a)

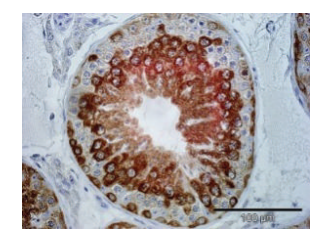

(b)

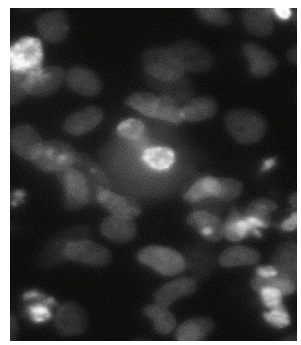

(d)

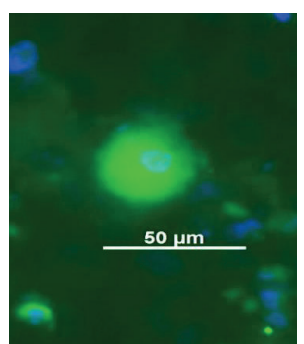

(e)

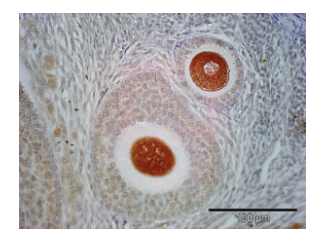

(c)

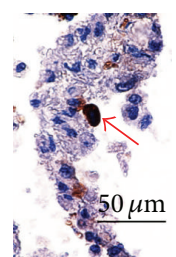

(f)

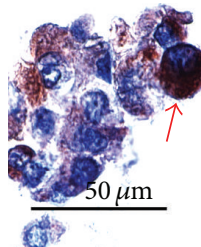

(g)

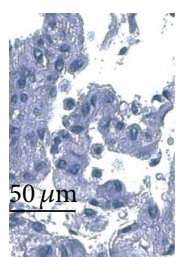

(h)

FIGURE 6: Characterization of the VASA antibody and detection of VASA-positive cells in OCCs. (a) Western blot analysis using marmoset monkey protein samples demonstrates the specificity of the VASA antibody. * indicates that the ovary was from an aged animal. The ovarian germ cell pool was therefore most likely strongly reduced or even exhausted leading to undetectable VASA protein concentrations in the sample. (b and c) Immunohistochemical application of the VASA antibody to marmoset gonads showed germ-cell-specific labeling in the adult testis and the adult ovary. (d) DAPI staining of a part of an OCC. Note the intensely stained nucleus in the central part. (e) The same area shown in (d). The large cell containing the intensely stained nucleus strongly stains for VASA. The signal is blurry due to the fact that the picture was taken through the bottom of a normal cell culture dish. ( $\mathrm{f}, \mathrm{g}$ ) Examples of isolated VASA-positive cells in sections of paraffinembedded OCCs.

is synthetized by the cells of the Corpus luteum. Neither estradiol nor progesterone was detected in medium samples. Moreover, FSHR transcripts were undetectable in OCC samples by deep sequencing and $L H / C G R$ abundance was lower than in neonatal ovary, fibroblasts, and ES cells (data not shown). Hence, the colonies do not consist of functional endocrine cells of the ovary.

3.6. Neither Teratoma Nor Ovarian Tissue Formation in a Subcutaneous Transplantation Assay. Subcutaneous transplantation of cells into immune-deficient mice is a useful approach to assay cells with regard to their differentiation capabilities, for example, the teratoma formation assay. Moreover, we have recently shown that single-cell suspensions derived from dissociated neonatal monkey testis can reconstitute complex testis tissue after transplantation into immune-deficient mice [24]. In order to test whether the OCCs have the ability to form ovarian tissue under the "in vivo" conditions after transplantation, we injected $\sim 10^{6}$ cells per mouse from the 5 th passage subcutaneously into 4 female adult NOD-SCID mice. Tissues from the injection site were collected for histological analysis after 15 weeks. Neither ovary-like tissue nor teratoma or any other conspicuous tissue was found (data not shown).

\section{Discussion}

A controversial debate on the presence of mitotically active germ line stem cells in the postnatal ovary characterized 
NANOG

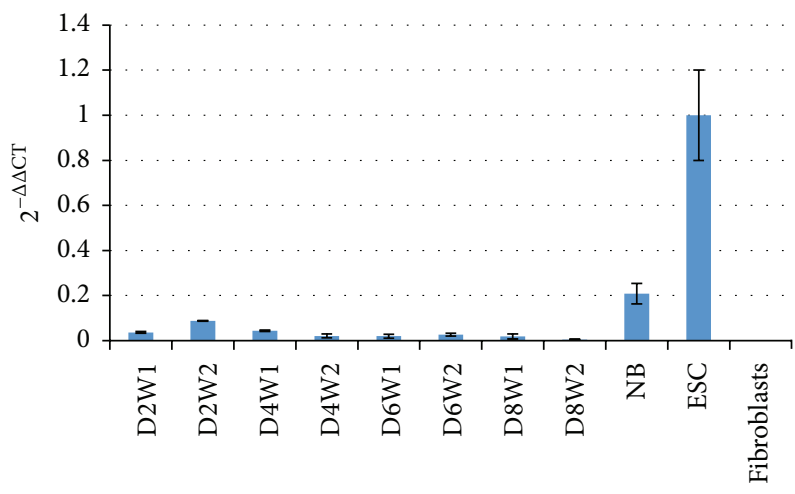

(a)

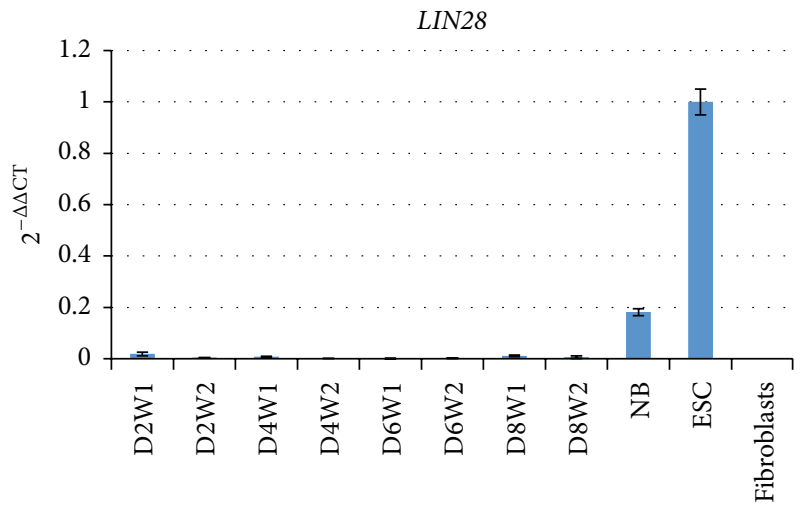

(c)

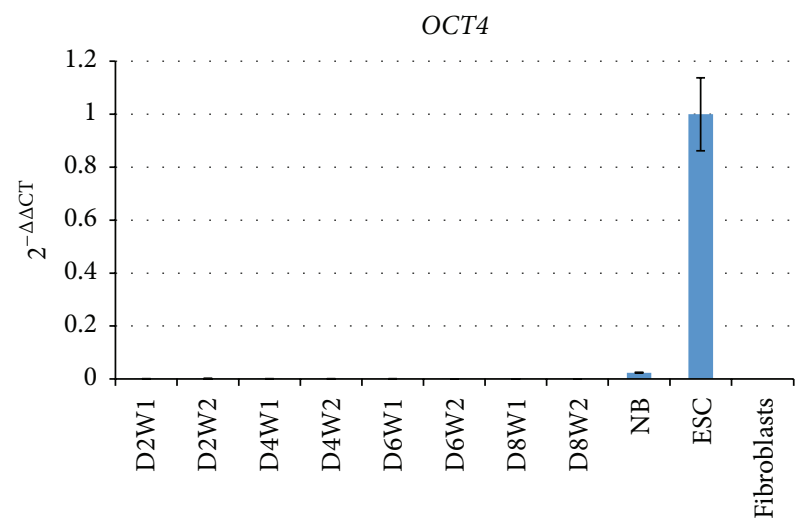

(b)

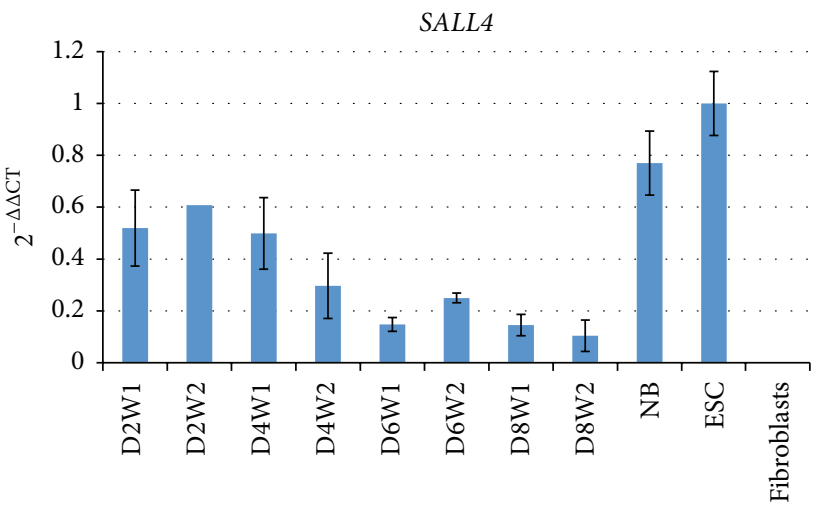

(d)

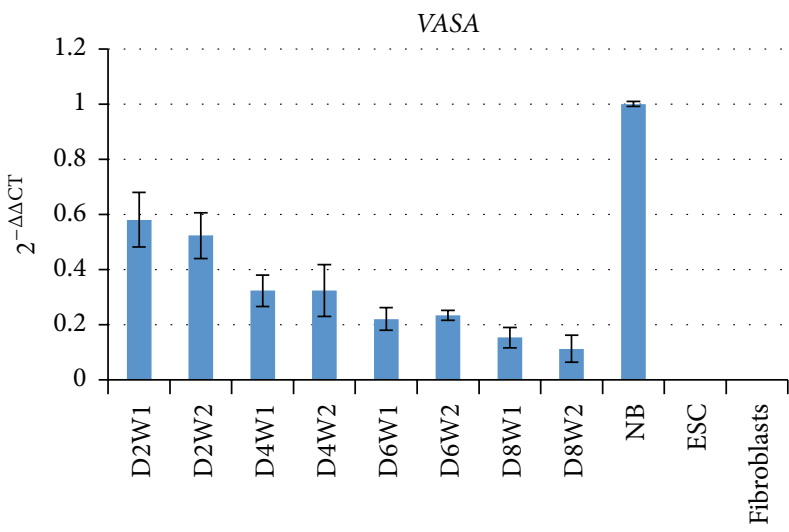

(e)

FIGURE 7: Pluripotency and germ cell marker mRNA abundance during the development of OCCs within one passage as revealed by real-time quantitative PCR. Positive controls for OCT4A, SALL4, and LIN28 were ES cells. Neonatal ovary was used as positive control for the germ cell marker VASA. NANOG was very low and OCT4A and LIN28 were absent at all time points analyzed. Relative abundance of SALL4 and VASA generally decreased with time during the culture period. D: days of culture. W: well for cell culture. NB: newborn ovary.

the last decade of ovarian germ cell research in mammals. Several reports provided data supporting the presence of ovarian germ line stem cells in postnatal mouse ovaries, for example, $[10,13,38]$, while other studies failed to identify female germ line stem cells, for example, [7, 8], thereby supporting the classical view of ovarian biology [1]. In primates including humans, the published data are similarly controversial and still not fully conclusive. Byskov et al. [3] failed to detect oogonia, which may be candidate cells for ovarian stem cells, in the postnatal human ovary older than two years, and even in younger postnatal ovaries the stem cell marker OCT4 was detectable only very rarely. We recently also failed to detect pluripotency and stem cell markerpositive cells in marmoset ovaries at one year of age [18]. On the other hand, White et al. [12] isolated mitotically active cells from human adult ovarian cortex that had the potential to form oocyte-like cells in vitro and to form ovarian follicles in a combined alloxenografting approach. Recently, however, 
Yuan et al. [9] failed to provide evidence for mitotically active germ line stem cells in rhesus monkeys (Macaca mulatta) and mice concluding that adult ovaries do not undergo germ cell renewal. Furthermore, almost ten years ago, Dyce et al. [17] reported that not only ovarian cells have the potential to develop female germ cells, but also fetal porcine skin cells have. They formed oocyte-like cells in vitro which were extruded from hormone-responsive follicle-like aggregates.

We have established a long-term cell culture system for neonatal marmoset monkey ovarian cells. Seeding of the marmoset monkey ovarian cell suspension onto the MEF cells resulted in the development of cell colonies morphologically resembling colonies which have been observed previously by different other groups for human [39] and mouse [38, 40] ovarian cell cultures. However, while these studies reported the robust expression of pluripotency markers such as OCT4 and NANOG and therefore claimed an ES cell-like character of the cells [40], we failed to detect these core pluripotency markers in marmoset ovarian cell cultures on the transcript and on the protein level (the latter not shown), although our starting material, that is, neonatal ovary, was positive for these factors. In fact, marmoset monkey primordial germ cells [19] and oogonia [18] robustly express OCT4. This discrepancy between the native premeiotic germ cells and the cultured ovarian cells shows that the marmoset OCCs did not contain remaining ("contaminating") primordial germ cells or oogonia. All our data point to the fact that premeiotic germ cells were absent from the early passages of the cultured ovarian cells. This is also in contrast to a publication on pig ovarian stem cells. Bui and colleagues [41] derived putative stem cells from adult pig ovary that gave rise to germ celllike cells corresponding to primordial germ cells. However, these cells, unlike the cells described in our present study, also robustly expressed pluripotency factors such as OCT4 and NANOG. Moreover, the phenotype of the pig cells in culture was different from the colonies observed in this study and other studies, for example, [40]. Interestingly, however, despite the clearly different starting conditions, both our and Bui's cell culture systems resulted in the development of large oocyte-like cells.

In addition to the absence of the pluripotency factors, we did not detect even a single DAZL, MAEL, RNF17, TEX12, TEX101, or TDRD1 transcript in OCCs of the 4th passage by deep sequencing, while all these germ cell transcripts were abundant in the neonatal ovary samples further supporting the absence of germ cells from the marmoset ovarian cell cultures at low passages. Hence, we conclude that marmoset monkey OCCs are neither germ cells nor pluripotent stem cells. The exact identity of the OCCs will be analyzed in future studies. However, despite showing morphology resembling an epithelium, the OCCs lacked characteristic proteins of epithelia like E-cadherin and cytokeratins. However, from OCC passage 4 onwards, we observed the development of individual oocyte-like cells strongly expressing the germ cell genes VASA, DAZL, NOBOX, DPPA3, and SALL4. Furthermore, also the meiotic marker $S C P 3$ was expressed in OLCs even though at moderate levels. In contrast, OCT4A, NANOG, and LIN28 were low in OLCs. In addition to the marker expression data on the mRNA level we wanted to confirm VASA also on the protein level. We detected robust VASA protein expression in OLCs. Altogether, this marker profile suggests that the OLCs may correspond to a late premeiotic stage. These characteristics are partly similar to those of the OLCs described by Dyce et al. [17]. However, Dyce and colleagues showed that OLCs developed from cell aggregates that detached from the cell culture surface and formed hormone-responsive follicle-like structures. Then, the OLCs were extruded from the follicles and released into the medium. From $\sim 500,000$ skin cells approximately $6-70$ large cells were extruded. Our findings were in the same range with typically 5-10 large OLCs per well and passage. But we never observed follicle-like structures. Moreover, we did not obtain any evidence for an endocrine regulation of OLC development in the marmoset monkey ovarian cell cultures.

Since we originally intended to culture oogonia, we spun down the cells down primary cells at $200 \mathrm{~g}$. This may be insufficient to quantitatively collect those cells in the pellet that were cultured in previous studies, where the ovarian germ line stem cells were sedimented at $300 \mathrm{~g}$ [13] or $1000 \mathrm{~g}$ [14], respectively. Based on this, we hypothesize that we collected in the present study oogonia (and other larger somatic cells) using a force of $200 \mathrm{~g}$ but only marginal amounts of the progenitors of the OLCs, which probably are a subpopulation of the OSE [14]. The oogonia apparently did not survive in our culture system. Therefore, we were unable to detect pluripotency markers in our culture and germ cell markers in the early passages. However, we further hypothesize that despite the low $g$ force applied in our study some OSE cells with stem cell capacity were still present in the culture. They were hypothetically able to develop into OLCs after more than three passages.

We also tested magnetic activated cell sorting (MACS) to enrich putative stem cells. However, MACS using, for example, TRA-1-81 antibodies was not successful. It must be noted, however, that the neonatal marmoset ovary is extremely tiny and that its availability is very limited. Indeed, the size of the neonatal ovary is only about $2 \mathrm{~mm} \times 1 \mathrm{~mm} \times$ $1 \mathrm{~mm}$. Hence, experimental refinement and cell enrichment approaches are extraordinarily challenging. Therefore, we decided in the present study to culture the unsorted cell population obtained after tissue digestion.

In summary, we have established a long-term neonatal marmoset monkey ovarian cell culture system. However, we failed to detect pluripotent stem and premeiotic germ cell markers in low OCC passages. From passage 4 onwards, however, OLCs developed and were still developing at high passages (>20) after more than 5 months of culture. Considering the marker expression data, the view of a germ cell identity of the OLCs appears justified. An essential prerequisite of gamete formation is meiosis [42]. Except for the expression of SCP3, which is an essential protein for meiotic synaptonemal complex formation, we obtained no evidence for meiotic entry of the OLCs except the formation of some structures morphologically resembling polar bodies. We also never observed a Zona pellucida. Altogether, OLCs generated in this culture system appear to be germ line cells, but they are neither functional female gametes nor do they represent meiotic germ cell stages. 
Currently it remains to be proven from which progenitor cells the OLCs develop in our culture system. So far, we were not able to identify these cells in the marmoset. However, a candidate tissue for the presence of ovarian stem cells with germ line potential could be the ovarian surface epithelium, which is discussed to be a multipotent tissue possibly harboring a stem or progenitor cell type [43]. In this regard, also the concept of the very small embryonic-like stem cells (VSELs) should be taken into account [16].

\section{Conclusion and Outlook}

In conclusion, we have established a nonhuman primate cell culture system that allows the long-term culture and development of OLCs from a nonhuman primate species. The vast majority of the cultured cells in this study, however, are neither pluripotent stem cells nor germ (line stem) cells, as has been suggested or shown in previous reports [38-40]. Future experiments should aim at resolving this discrepancy and test whether this is a species-specific phenomenon.

Future experiments will also aim at the identification and functional characterization of the stem/progenitor cell population in the marmoset culture system. Furthermore, protocols are needed that support the entry of the OLCs into meiosis potentially giving rise to mature oocytes in the future. Besides functional testing of these cells, their correct epigenetic state needs to be confirmed. In the future, a refined culture system based on the one described here may allow more detailed in vitro studies on early phases of primate germ cell development and on the molecular and cellular identity of OLCs and their progenitors in an experimentally accessible NHP system. In the long term, this may also contribute in the future to the development of novel therapeutic approaches of female infertility.

\section{Conflict of Interests}

The authors declare that there is no conflict of interests that could be perceived as prejudicing the impartiality of the research reported.

\section{Authors' Contribution}

Bentolhoda Fereydouni carried out conception and design, collection and assembly of data, data analysis and interpretation, paper writing, and final approval of paper. Gabriela Salinas-Riester carried out collection and assembly of data, data analysis and interpretation, paper writing, and final approval of paper. Michael Heistermann carried out collection and assembly of data, data analysis and interpretation, and final approval of paper. Ralf Dressel carried out financial support, collection and/or assembly of data, and final approval of paper. Lucia Lewerich carried out collection and/or assembly of data, data analysis and interpretation, and final approval of paper. Charis Drummer carried out provision of study material and final approval of paper. Rüdiger Behr carried out conception and design, financial support, collection and/or assembly of data, data analysis and interpretation, paper writing, and final approval of paper.

\section{Acknowledgments}

The authors appreciate the excellent assistance and the support of Nicole Umland, Angelina Berenson, and Gesche Spehlbrink. They are also very thankful to Erika Sasaki for providing the ES cells, Katharina Debowski for ES cell culture, and the members of the animal facility for excellent animal husbandry. They thank Ellen Wiese for administrative support. The support of Bentolhoda Fereydouni by the scholarship of the Deutscher Akademischer Austauschdienst (DAAD) is gratefully acknowledged. Bentolhoda Fereydouni is on a scholarship of the Deutscher Akademischer Austauschdienst (DAAD). The work was mainly supported by institutional resources and marginally by a grant of the Deutsche Forschungsgemeinschaft (DFG; Be2296-6) entitled "Pluripotent cells from marmoset testis" to Rüdiger Behr. The cell injection assays in mice performed by Ralf Dressel were supported by a Collaborative Research Centre from the Deutsche Forschungsgemeinschaft (SFB1002, TP C05).

\section{References}

[1] S. Zuckerman, "The number of oocytes in the mature ovary," Recent Progress in Hormone Research, vol. 6, pp. 63-108, 1951.

[2] A. G. Byskov, M. J. Faddy, J. G. Lemmen, and C. Y. Andersen, "Eggs forever?" Differentiation, vol. 73, no. 9-10, pp. 438-446, 2005.

[3] A. G. Byskov, P. E. Høyer, C. Yding Andersen, S. G. Kristensen, A. Jespersen, and K. Møllgård, "No evidence for the presence of oogonia in the human ovary after their final clearance during the first two years of life," Human Reproduction, vol. 26, no. 8, pp. 2129-2139, 2011.

[4] Y. Liu, C. Wu, Q. Lyu et al., "Germline stem cells and neooogenesis in the adult human ovary," Developmental Biology, vol. 306, no. 1, pp. 112-120, 2007.

[5] E. Bendsen, A. G. Byskov, C. Y. Andersen, and L. G. Westergaard, "Number of germ cells and somatic cells in human fetal ovaries during the first weeks after sex differentiation," Human Reproduction, vol. 21, no. 1, pp. 30-35, 2006.

[6] H. Stoop, F. Honecker, M. Cools, R. de Krijger, C. Bokemeyer, and L. H. J. Looijenga, "Differentiation and development of human female germ cells during prenatal gonadogenesis: an immunohistochemical study," Human Reproduction, vol. 20, no. 6, pp. 1466-1476, 2005.

[7] H. Zhang, W. Zheng, Y. Shen, D. Adhikari, H. Ueno, and K. Liu, "Experimental evidence showing that no mitotically active female germline progenitors exist in postnatal mouse ovaries," Proceedings of the National Academy of Sciences of the United States of America, vol. 109, no. 31, pp. 12580-12585, 2012.

[8] L. Lei and A. C. Spradling, "Female mice lack adult germline stem cells but sustain oogenesis using stable primordial follicles," Proceedings of the National Academy of Sciences of the United States of America, vol. 110, no. 21, pp. 8585-8590, 2013.

[9] J. Yuan, D. Zhang, L. Wang et al., "No evidence for neooogenesis may link to ovarian senescence in adult monkey," Stem Cells, vol. 31, no. 11, pp. 2538-2550, 2013. 
[10] J. Johnson, J. Canning, T. Kaneko, J. K. Pru, and J. L. Tilly, "Germline stem cells and follicular renewal in the postnatal mammalian ovary," Nature, vol. 428, no. 6979, pp. 145-150, 2004.

[11] J. Johnson, J. Bagley, M. Skaznik-Wikiel et al., "Oocyte generation in adult mammalian ovaries by putative germ cells in bone marrow and peripheral blood," Cell, vol. 122, no. 2, pp. 303-315, 2005.

[12] Y. A. R. White, D. C. Woods, Y. Takai, O. Ishihara, H. Seki, and J. L. Tilly, "Oocyte formation by mitotically active germ cells purified from ovaries of reproductive-age women," Nature Medicine, vol. 18, no. 3, pp. 413-421, 2012.

[13] K. Zou, Z. Yuan, Z. Yang et al., "Production of offspring from a germline stem cell line derived from neonatal ovaries," Nature Cell Biology, vol. 11, no. 5, pp. 631-636, 2009.

[14] A. Bukovsky, M. Svetlikova, and M. R. Caudle, "Oogenesis in cultures derived from adult human ovaries," Reproductive Biology and Endocrinology, vol. 3, article 17, 2005.

[15] I. Virant-Klun, N. Zech, P. Rožman et al., "Putative stem cells with an embryonic character isolated from the ovarian surface epithelium of women with no naturally present follicles and oocytes," Differentiation, vol. 76, no. 8, pp. 843-856, 2008.

[16] S. Parte, D. Bhartiya, J. Telang et al., "Detection, characterization, and spontaneous differentiation in vitro of very small embryonic-like putative stem cells in adult mammalian ovary," Stem Cells and Development, vol. 20, no. 8, pp. 1451-1464, 2011.

[17] P.-W. Dyce, L. Wen, and J. Li, "In vitro germline potential of stem cells derived from fetal porcine skin," Nature Cell Biology, vol. 8, no. 4, pp. 384-390, 2006.

[18] B. Fereydouni, C. Drummer, N. Aeckerle, S. Schlatt, and R. Behr, "The neonatal marmoset monkey ovary is very primitive exhibiting many oogonia," Reproduction, vol. 148, no. 2, pp. 237247, 2014.

[19] N. Aeckerle, C. Drummer, K. Debowski, C. Viebahn, and R. Behr, "Primordial germ cell development in the marmoset monkey as revealed by pluripotency factor expression: suggestion of a novel model of embryonic germ cell translocation," Molecular Human Reproduction, vol. 21, no. 1, pp. 66-80, 2015.

[20] T. Müller, G. Fleischmann, K. Eildermann et al., "A novel embryonic stem cell line derived from the common marmoset monkey (Callithrix jacchus) exhibiting germ cell-like characteristics," Human Reproduction, vol. 24, no. 6, pp. 1359-1372, 2009.

[21] K. Debowski, R. Warthemann, J. Lentes et al., "Non-viral generation of marmoset monkey iPS cells by a six-factor-inone-vector approach," PLoS ONE, vol. 10, no. 3, 2015.

[22] M. Heistermann, S. Tari, and J. K. Hodges, "Measurement of faecal steroids for monitoring ovarian function in new world primates, callitrichidae," Journal of Reproduction and Fertility, vol. 99, no. 1, pp. 243-251, 1993.

[23] M. Heistermann, M. Finke, and J. K. Hodges, "Assessment of female reproductive status in captive-housed Hanuman langurs (Presbytis entellus) by measurement of urinary and fecal steroid excretion patterns," American Journal of Primatology, vol. 37, no. 4, pp. 275-284, 1995.

[24] N. Aeckerle, R. Dressel, and R. Behr, "Grafting of neonatal marmoset monkey testicular single-cell suspensions into immunodeficient mice leads to ex situ testicular cord neomorphogenesis," Cells Tissues Organs, vol. 198, no. 3, pp. 209-220, 2013.

[25] R. M. Perrett, L. Turnpenny, J. J. Eckert et al., "The early human germ cell lineage does not express SOX2 during in vivo development or upon in vitro culture," Biology of Reproduction, vol. 78 , no. 5, pp. 852-858, 2008.
[26] K. Eildermann, N. Aeckerle, K. Debowski et al., “Developmental expression of the pluripotency factor sal-like protein 4 in the monkey, human and mouse testis: restriction to premeiotic germ cells," Cells Tissues Organs, vol. 196, no. 3, pp. 206-220, 2012.

[27] N. Aeckerle, K. Eildermann, C. Drummer et al., "The pluripotency factor LIN28 in monkey and human testes: a marker for spermatogonial stem cells?" Molecular Human Reproduction, vol. 18, no. 10, Article ID gas025, pp. 477-488, 2012.

[28] D. H. Castrillon, B. J. Quade, T. Y. Wang, C. Quigley, and C. P. Crum, "The human VASA gene is specifically expressed in the germ cell lineage," Proceedings of the National Academy of Sciences of the United States of America, vol. 97, no. 17, pp. 95859590, 2000.

[29] Y. Lin, M. E. Gill, J. Koubova, and D. C. Page, "Germ cellintrinsic and -extrinsic factors govern meiotic initiation in mouse embryos," Science, vol. 322, no. 5908, pp. 1685-1687, 2008.

[30] A. Rajkovic, S. A. Pangas, D. Ballow, N. Suzumori, and M. M. Matzuk, "NOBOX deficiency disrupts early folliculogenesis and oocyte-specific gene expression," Science, vol. 305, no. 5687, pp. 1157-1159, 2004.

[31] Y.-J. Liu, T. Nakamura, and T. Nakano, "Essential role of DPPA3 for chromatin condensation in mouse oocytogenesis," Biology of Reproduction, vol. 86, no. 2, article 40, 2012.

[32] M. Sato, T. Kimura, K. Kurokawa et al., "Identification of PGC7, a new gene expressed specifically in preimplantation embryos and germ cells," Mechanisms of Development, vol. 113, no. 1, pp. 91-94, 2002.

[33] Y. Ohinata, B. Payer, D. O'Carroll et al., "Blimpl is a critical determinant of the germ cell lineage in mice," Nature, vol. 436, no. 7048, pp. 207-213, 2005.

[34] M. Yamaji, Y. Seki, K. Kurimoto et al., "Critical function of Prdm14 for the establishment of the germ cell lineage in mice," Nature Genetics, vol. 40, no. 8, pp. 1016-1022, 2008.

[35] F. Sugawa, M. J. Arauzo-Bravo, J. Yoon et al., "Human primordial germ cell commitment in vitro associates with a unique PRDM14 expression profile," The EMBO Journal, vol. 34, no. 8, pp. 1009-1024, 2015.

[36] R. Warthemann, K. Eildermann, K. Debowski, and R. Behr, "False-positive antibody signals for the pluripotency factor OCT4A (POU5F1) in testis-derived cells may lead to erroneous data and misinterpretations," Molecular Human Reproduction, vol. 18, no. 12, pp. 605-612, 2012.

[37] R. Ivell, K. Teerds, and G. E. Hoffman, "Proper application of antibodies for immunohistochemical detection: antibody crimes and how to prevent them," Endocrinology, vol. 155, no. 3, pp. 676-687, 2014.

[38] J. Pacchiarotti, C. Maki, T. Ramos et al., "Differentiation potential of germ line stem cells derived from the postnatal mouse ovary," Differentiation, vol. 79, no. 3, pp. 159-170, 2010.

[39] M. Stimpfel, T. Skutella, B. Cvjeticanin et al., "Isolation, characterization and differentiation of cells expressing pluripotent/multipotent markers from adult human ovaries," Cell and Tissue Research, vol. 354, no. 2, pp. 593-607, 2013.

[40] S. P. Gong, S. T. Lee, E. J. Lee et al., "Embryonic stem celllike cells established by culture of adult ovarian cells in mice," Fertility and Sterility, vol. 93, no. 8, pp. 2594.e9-2601.e9, 2010.

[41] H.-T. Bui, N. Van Thuan, D.-N. Kwon et al., "Identification and characterization of putative stem cells in the adult pig ovary," Development, vol. 141, no. 11, pp. 2235-2244, 2014. 
[42] M. A. Handel, J. J. Eppig, and J. C. Schimenti, "Applying 'gold standards' to in-vitro-derived germ cells," Cell, vol. 157, no. 6, pp. 1257-1261, 2014.

[43] A. Bukovsky, M. R. Caudle, I. Virant-Klun et al., "Immune physiology and oogenesis in fetal and adult humans, ovarian infertility, and totipotency of adult ovarian stem cells," Birth Defects Research Part C: Embryo Today: Reviews, vol. 87, no. 1, pp. 64-89, 2009. 

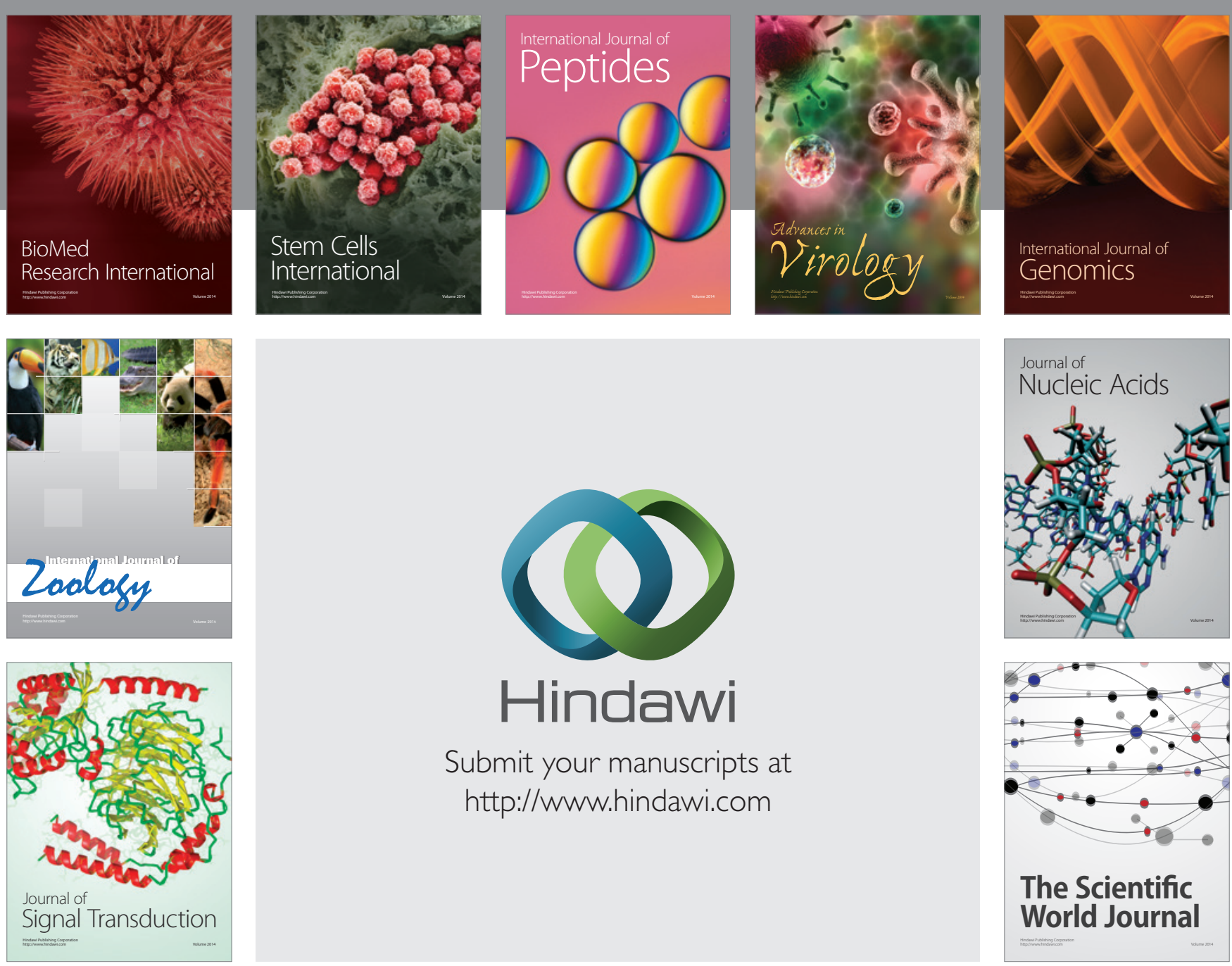

Submit your manuscripts at

http://www.hindawi.com
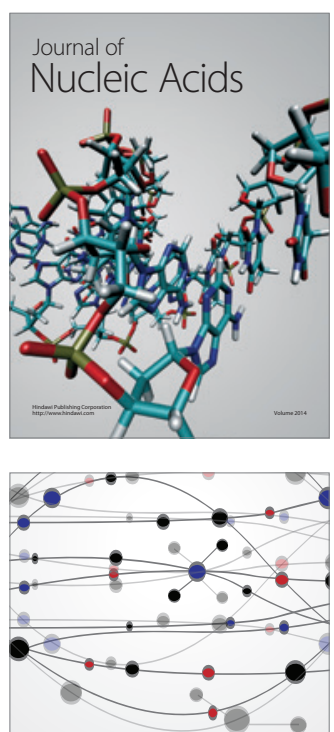

The Scientific World Journal
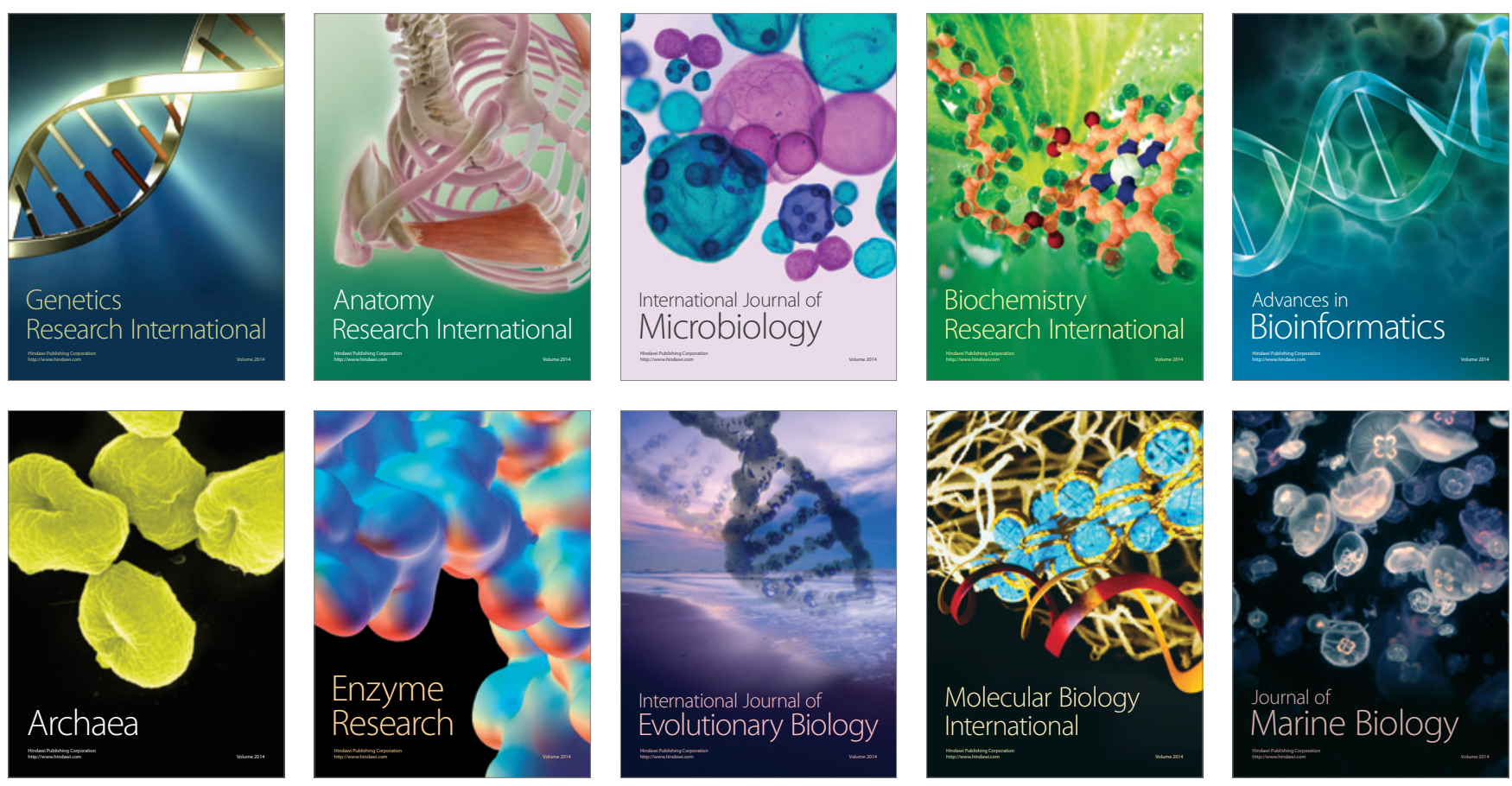